\title{
Patterns of cell motility in the organizer and dorsal mesoderm of Xenopus
}

\section{laevis}

\author{
JOHN SHIH* and RAY KELLER \\ Division of Cell and Developmental Biology, Department of Molecular and Cell Biology, University of California, Berkeley, Berkeley, CA 94720, USA \\ *Present Address: Beckman Institute, California Institute of Technology, Pasadena, CA, USA
}

\section{Summary}

In a companion paper (Shih, J. and Keller, R. (1992) Development 116, 901-914), we described a sequence of cell behaviors, called mediolateral intercalation behavior (MIB), that produces mediolateral cell intercalation, the process that drives convergence and extension of the axial and paraxial mesoderm of Xenopus. In this paper, we describe the pattern of expression of MIB in the mesoderm during gastrulation, using video image processing and recording of cell behavior in 'shaved', openfaced explants of the marginal zone. At midgastrula stage (10.5), MIB begins at two dorsolateral sites in the prospective anterior mesoderm and progresses medially along two arcs that lengthen toward and meet at the midline to form a single arc of cells expressing MIB, called the vegetal alignment zone (VgAZ). The notochordal-somitic mesodermal boundary forms within the VgAZ at stage 11, and then progresses animally and laterally, along the prospective anterior-posterior axis, eventually bounding a trapezoidal area the shape of the fate-mapped notochord. Meanwhile, from its origin in the $\mathrm{VgAZ}$, MIB spreads in the prospective posterior direction along the lateral boundaries of both the notochordal and somitic mesoderm. From there it spreads medially in both tissues. Subsequently, vacuolation of notochord cells, and segmentation and expression of a somite-specific marker repeat the progression of mediolateral intercalation behavior. Thus cells in the posterior, medial regions of the notochordal and the somitic territories are the last to express mediolateral intercalation behavior and subsequent tissue differentiations. In explants that do not converge, these cells neither express mediolateral intercalation behavior nor differentiate. These facts suggest that progressions of MIB in the anterior-posterior and lateral-medial directions may be organized by signals emanating from the lateral somitic and notochordal boundaries. These signals may have limited range and may be dependent on convergence, driven by mediolateral cell intercalation, to bring cells within their range. In the embryo, the posterior progression of MIB results in arcs of convergence, anchored in the vegetal endoderm at each end, acting on the inside of the blastoporal lip to produce involution of the IMZ.

Key words: gastrulation, Xenopus, cell motility, boundary formation, cell alignment, cell intercalation, morphogenesis, tissue differentiation.

\section{Introduction}

In this paper, we examine the pattern of morphogenetic cell behavior in the dorsal, axial mesoderm of Xenopus. Mesoderm plays a major role in the organization and patterning of the embryo. Spemann and Mangold (1924) demonstrated the role of the dorsal mesoderm (the Spemann organizer) in neural induction (also see Spemann, 1938; Mangold, 1933; Holtfreter, 1933a-d; Keller et al. 1992a,b; see Nieuwkoop, 1973 for a review). Additional studies have clarified the role of the dorsal mesoderm in assimilative induction, the recruitment of lateral and ventral mesoderm into dorsal axial structures (see page 163, Spemann, 1938; Cooke, 1972, 1975, 1985, 1989; Dale and Slack, 1987; Stewart, 1991; see Cooke, 1991 and Gerhart et al., 1991). The morphogenetic functions of notochordal and somitic mesoderm, which form the structural framework of the vertebrate body plan, have been studied extensively (Schechtman, 1942; Holtfreter, 1939, 1943a,b, 1944; Nakatsuji, 1975, 1984; Keller, 1981, 1984; Keller et al., 1985a,b; Nakatsuji and Johnson, 1983; Shi et al., 1987, 1989; Winklbauer, 1990; Winklbauer and Nagel, 1991).

There is evidence that proper gastrulation movements depend on precise patterning of mesoderm morphogenesis (Keller, 1986; Keller et al., 1991a,b). The early-involuting, leading edge of the mesodermal mantle shows directed migration across the roof of the blastocoel (see Nakatsuji, 1975; Winklbauer, 1990; Winklbauer and Nagel, 1991), where it differentiates into head (prechordal), heart, lateral plate and blood islands. In contrast, the late-involuting, axial and paraxial mesoderm shows the powerful convergence and extension movements that alone can drive invo- 
lution and blastopore closure (Keller et al., 1985a,b; Keller and Jansa, 1992). Convergence and extension are driven by radial and mediolateral intercalations of deep mesodermal cells (Keller and Tibbetts, 1989; Wilson et al., 1989; Keller et al., 1989a; Wilson and Keller, 1991; Shih and Keller, 1992a). These two types of cell intercalations are highly patterned in the neurula (Wilson et al., 1989; Keller et al., 1989a), suggesting that patterning of cell behaviors also might be a fundamental part of the preceding gastrulation movements. But observations of mesodermal cells in openfaced explants reveal only a weak anterior-posterior progression of cell behavior during gastrulation (Wilson and Keller, 1991).

However, it is not the deepest mesodermal cells, which were viewed in the open-faced explants, but the ones immediately beneath the overlying endodermal epithelium that are strongly patterned. In a companion paper, we show that the endodermal epithelium can organize convergence and extension of the underlying deep cells, suggesting that those cells closest to the organizing epithelium might be the first to respond with specific cell behaviors driving convergence and extension (Shih and Keller, 1992b). The mesodermal cells immediately beneath the endodermal epithelium of the DMZ show a highly organized morphology and arrangement (Keller et al., 1989b). When these cells are exposed in 'shaved', open-faced explants, they show a highly organized sequence of events, called mediolateral intercalation behavior (MIB), that drive mediolateral intercalation (Shih and Keller, 1992a). MIB consists of bipolar, medially and laterally directed protrusive activity, which exerts traction on adjacent mesodermal cells' surfaces, and thus produces mediolateral cell elongation, alignment and intercalation (Shih and Keller, 1992a).

In this paper, we use the shaved, open-faced explant preparation to follow the progression of mediolateral intercalation behavior and subsequent tissue differentiation over large fields of deep mesodermal cells through gastrulation and neurulation. These observations reveal that this behavior is highly patterned with respect to the lateral-medial and anterior-posterior axes, and with respect to the notochord and somitic territories. These patterns have important implications for how the mesodermal tissues are organized and how convergence and extension function to bring about involution and extend the embryonic axis.

\section{Materials and methods}

The methods used in this paper follow closely those described in the companion paper (Shih and Keller, 1992a). Eggs were obtained, dejellied and labelled with 10-15 nl of FDX 10,000 (Sigma Chemical Company) made up at $25 \mathrm{mg} / \mathrm{ml}$ in $0.2 \mathrm{~N} \mathrm{KCl}$ (Gimlich and Braun, 1985) as described previously (Shih and Keller, 1992a). Shaved open-faced explants of the dorsal marginal zone (DMZ) were made as described previously (Shih and Keller, 1992a). For low-light filming, FDX-labelled deep mesodermal cells were added to the inner (deep) surface of unlabelled 'host' explants. Labelled cells were taken from sibling FDX-labelled embryos by peeling back the suprablastoporal endodermal epithelium and teasing out a small number of cells from the presumptive chordamesoderm lying beneath the epithelium. These labelled cells were added to the same region of unlabelled, shaved explants

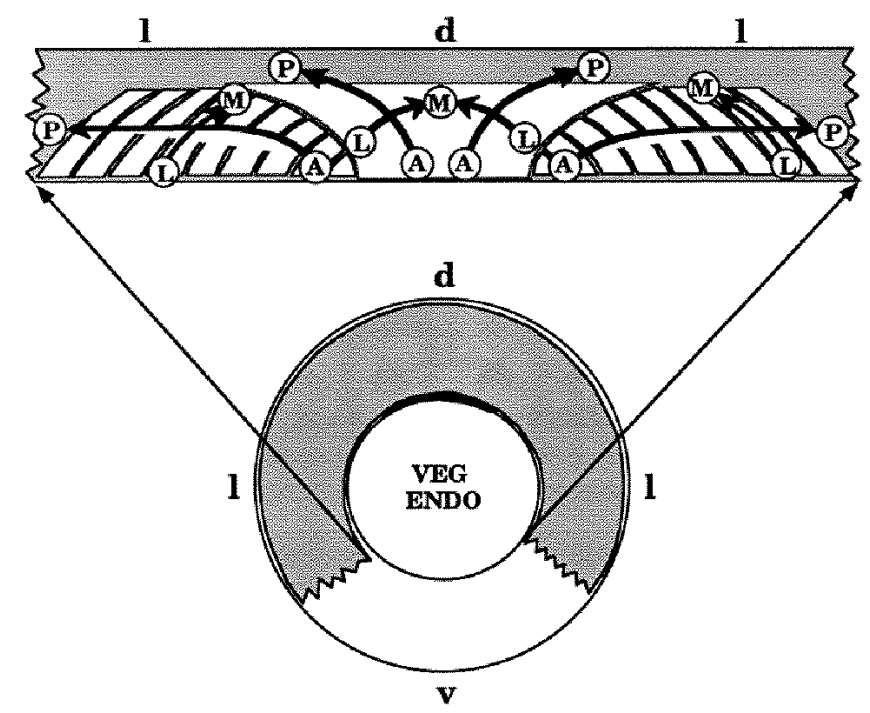

Fig. 1. This study uses large, 'shaved' open-faced explants of the marginal zone (top diagram), excised from the early Xenopus gastrula (bottom diagram). In the bottom diagram, the dorsal (d), lateral (l) and ventral (v) sectors of the marginal zone are shown as viewed from the vegetal pole of the early gastrula. The top diagram shows the prospective mesodermal tissues as they would appear in the shaved explant if the outer layer of prospective endoderm covering them was removed. The prospective anterior (A)-to-posterior (P) and prospective lateral (L)-to-medial (M) axes of both the prospective notochordal (solid center area) and somitic mesoderm (bars) are shown. The arrows point in the direction of the progression of the cell behaviors and tissue differentiations described in this paper. In our experiments, the motility and differentiation of the mesoderm was viewed from the opposite, inner surface of the explant.

of the same stage, and the host explants were cultured in Shihmodified Danilchik's solution (SMD: see Keller, 1991).

Cell behaviors are described below with respect to the prospective lateral-medial and anterior-posterior axes of the notochordal and somitic mesoderm, as they map back to large, shaved explants of the involuting marginal zone (IMZ) (Fig. 1). Note that the prospective anterior-posterior axis of the notochord runs from vegetal-to-animal at the midline but in the prospective lateral region it curves into the lateral sector of the IMZ. This curvature is extreme in the case of the prospective somite files, which have their prospective anterior-posterior axes curved laterally and ventrally in the IMZ. Note also that the prospective lateral edges of the somitic mesoderm lie next to where the vegetal endoderm was attached. The medial edges of the first six or seven somites bound the notochord, whereas the remaining ones do not, at least at the surface immediately beneath the endoderm; the notochord shears posteriorly along the medial edges of these posterior somites in the neurula stage (see the text and Fig. 5, Keller et al., 1991a, for details).

Whole-mount staining of somitic mesoderm, microscopy under epi-illumination, fluorescence microscopy, video recording and image processing were done as described previously (Shih and Keller, 1992a). The embryos were fixed, dissected and prepared for scanning electron microscopy by methods described previously (Keller et al., 1989a). We digitized cell shapes by tracing images from video monitors to mylar sheets and digitizing them on a Summasketch tablet (Summagraphics). Parameters of cell morphology were quantified from the digitized data as described previously (Shih and Keller, 1992a). 


\section{Results}

We will describe the patterns of expression of MIB in the mesoderm by using cell elongation and alignment as indicators of MIB. Cell elongation and alignment are reliable and useful indicators of MIB because they always accompany MIB and presence of elongated, aligned cells was always associated with the bipolar, mediolaterally directed protrusive activity that defines MIB (Shih and Keller, 1992a). We distinguish between MIB and mediolateral intercalaton itself because MIB always produces elongation and alignment but not necessarily mediolateral intercalation. Patterns of MIB will be examined in explants that $d o$ extend, in which case MIB produces elongation, alignment and intercalation, and in those that do not extend, in which case MIB produces elongation and alignment, but little or no effective intercalation (see Shih and Keller, 1992a).

\section{Formation of the vegetal alignment zone ( $V g A Z)$}

Most or all of the dorsal mesodermal cells divide in the first part of gastrulation (Shih and Keller, 1992a). Then MIB begins during the early part of stage 10.5, two hours after the onset of gastrulation, and results in formation of the vegetal alignment zone ( $\mathrm{VgAZ})$. The cells at the vegetal end of the explants begin to elongate, increasing their length/width ratio (LWR) and aligning parallel to one another in an arc lying 3 to 7 cells from the vegetal end of the explant (Fig. 2; also see Fig. 2, Shih and Keller, 1992a). The lateral ends of the bilateral arcs lie about 15 degrees on each side of the dorsal midline. The elongated cells within the arcs are aligned perpendicular to the prospective anterior-posterior axis of the mesoderm (Fig. 2). The cell elongation and alignment that define the $\mathrm{VgAZ}$ develop progressively, beginning laterally and proceeding medially (Fig. 2, stage 10.5-11). Through stage 10 the mean LWR of cells in the prospective VgAZ is about 1.48 (Shih and Keller, 1992a). In early stage 10.5 , the average LWR of cells in lateral sectors of the $\mathrm{VgAZ}$ rises above that of medial sectors. This trend continues into stage 10.75 (Fig. 3 ) when the LWR of the medial sector 5 differs significantly from that in lateral sectors $1 \quad(P<0.002)$ and 9 $(P<0.005)$. After another hour (stage $11+)$, the mean LWR of medial cells approaches that of lateral cells (Fig. 3) and medial and lateral sectors may or may not show significant differences. For example, at stage 11, positions 6 and 11 differ significantly $(P<0.033)$ while positions 1 through 9 have a greater than $50 \%$ probability of being the same data set (average $P>0.5$ ). The lateral-to-medial progression is due to local changes in cell shape rather than movement and sorting of elongated cells. Local mediolateral intercalation occurs, but no long-range movements and sorting of cells by shape occurs. Slight left-right asymmetries in both directions are typical of this and other parameters of mesodermal development.

Ignoring the medial-lateral differences, the average LWRs of all $\mathrm{VgAZ}$ cells is 1.8 at stage 10.5, 2.0 at stage 10.75 and 2.3 at stage $11+$. These differ significantly from one another in either paired or unpaired Student's analysis $(P<0.01$ for stage 10.5 versus 10.75 , and $P<0.003$ for stage 10.75 versus $11+$ ). By stage 12 , the mean LWR of the VgAZ has reached 3.2 (Shih and Keller, 1992a). By stage

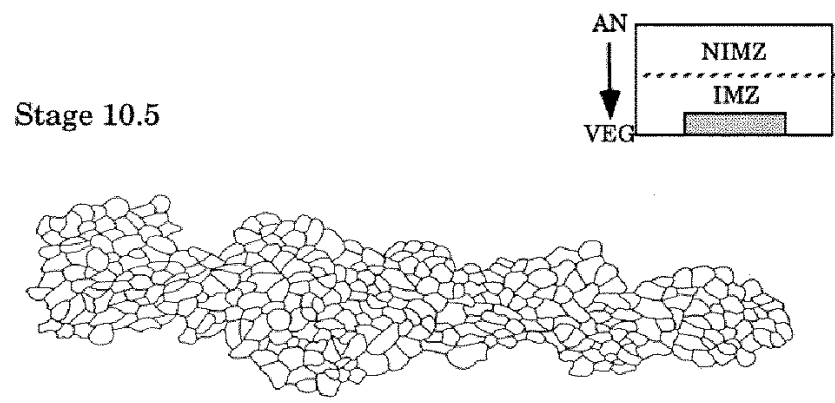

Stage 10.75

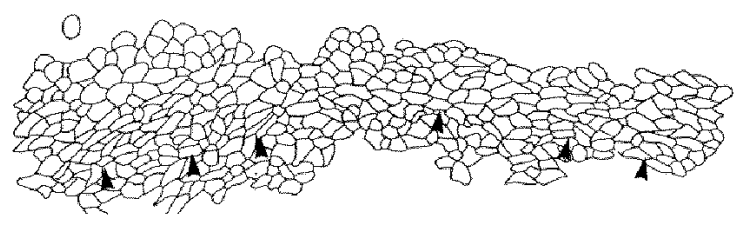

Stage 11

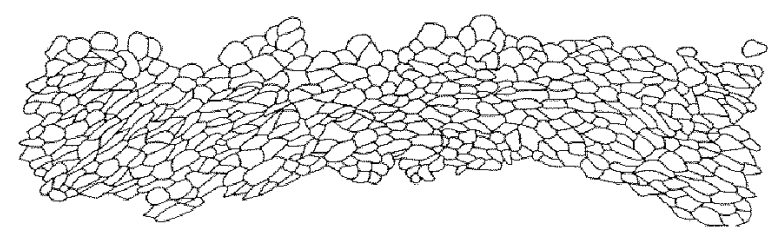

Fig. 2. The changes in cell shape and alignment that constitute formation of the vegetal alignment zone (VgAZ) are shown as tracings of a video recording of deep mesodermal cells in a shaved explant at stages $10.5,10.75$ and 11 . The location of this region of the involuting marginal zone (IMZ) is shown by the shaded area in the diagram at the upper right; the noninvoluting marginal zone (NIMZ) and the animal (AN)-to-vegetal (VEG) axis is also shown. The pointers indicate cells participating in formation of the $\mathrm{VgAZ}$. A light micrograph of the $\mathrm{VgAZ}$ is shown in Fig. 13A.

$11+$, the notochordal-somitic mesodermal boundaries form within the $\mathrm{VgAZ}$, as described below, thus separating the lateral somitic from the medial notochordal region.

The VgAZ is defined as an arc of cells with noticeably larger LWRs at stage 11 or $11+$. Development of the $\mathrm{VgAZ}$ is described by measuring the LWRs in mediolateral sectors of the same cell population at earlier stages (Figs 2, 3 ). The LWR of the definitive $\mathrm{VgAZ}$ at stage $11+$ (above), is significantly different $(P<0.001)$ from the mean LWR $(1.3 \pm 0.04)$ of the population immediate animal to the $\mathrm{VgAZ}$. If the boundaries of the $\mathrm{VgAZ}$ had been chosen too broadly, cells with low LWRs would have been included and the difference between cells inside and outside the $\mathrm{VgAZ}$ would have been masked. If the boundaries had been chosen too conservatively, elongated $\mathrm{VgAZ}$ cells would have been included in the external region, again masking the difference between it and the VgAZ.

The VgAZ expands animally in the prospective posterior direction (see Fig. 1), growing from 2-6 cells in animalvegetal extent to 4-12 cells (depending on the amount of extension) when the notochordal-somitic mesoderm bound- 


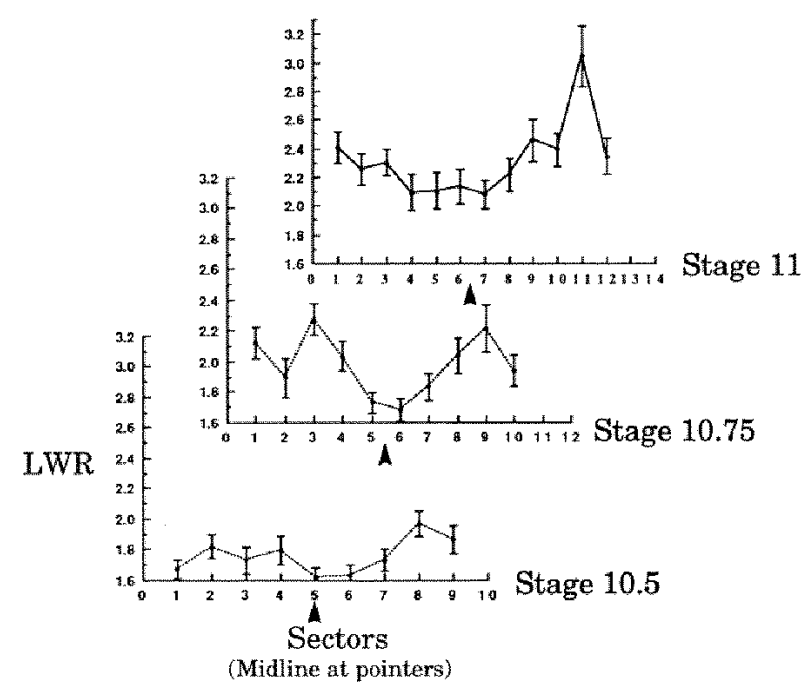

Fig. 3. The spatial and temporal progression of change in mean length/width ratio (LWR) of mesodermal cells in the $\mathrm{VgAZ}$ is illustrated by three graphs, using data obtained from the tracings in Fig. 1. The mean LWR, with the standard error of the mean, is plotted for 4 to 6 sectors on both sides of the midline of the $\mathrm{VgAZ}$ for stages 10.5, 10.75 and 11. Mean LWR increases with stage of development. Rise in mean LWR occurs in lateral sectors before medial sectors. Similar graphs of the maximum LWR in each sector and of the percentage of cells having LWRs greater than 2.0 show the same increase with stage and the same lateral-tomedial progression (plots not shown).

ary forms at stage $11+$ to 12 . In explants that do not converge and extend, this lengthening is due solely to expression of mediolateral intercalation behavior in more posterior cells. In explants that do converge and extend, the $\mathrm{VgAZ}$ also lengthens by mediolateral intercalation and thus extension of its original population.

\section{Formation of the notochord-somitic mesoderm boundaries}

The notochordal-somitic boundaries first appear as distinct, optically dark regions (under epi-illumination) between no more than two or three prospective notochord and somite cells lying within the VgAZ during stage 11 (Fig. 4, 0 and 2 hours). These initial boundaries are very short and stable, and form at the same sites within the VgAZ in all explants. In explants that converge and extend very little or not at all, the boundaries lengthen primarily by arcing animally and laterally (Fig. 4, 2.2-6.2 hours), along the anterior-posterior axis of the notochord, tracing out the notochord in a shape predicted by the fate map (Keller, 1976). When convergence and extension occur, mediolateral cell intercalation reduces the width of the notochord. In the embryo, this is extreme, reducing the notochord to less than two cells in width and greatly increasing its length (see Keller et al., 1989a; Wilson et al., 1989). The notochordal-somitic mesodermal boundaries also extend a short distance anteriorly, through the rest of the $\mathrm{VgAZ}$. With the exceptions noted below, cells do not cross these boundaries.

Two distinct cell populations are involved in formation of the notochordal-somitic boundaries. The initial, anterior boundaries form in the $\mathrm{VgAZ}$ among cells that are already expressing MIB and intercalating (see Shih and Keller, 1992a). In this region, tongues of notochordal and somitic cells often extend into the opposite territory and are withdrawn as development proceeds (note the tongue of notochord, white pointer, Fig. 4, 3-6.5 hours). In contrast, the boundaries in the posterior region form among cells not yet expressing MIB, and these tongues do not occur. In either case prospective notochordal and somitic cells are not mixed extensively when traced back to stage 10.5 , prior to boundary formation (Fig. 5). Although the notochord population itself is fairly contiguous, the notochord cells that form the initial boundary at stage 11.5-12 do not form a coherent population when traced back to the pre-boundary stage 10.5 (Fig. 6). Thus within the prospective notochord tissue, there does not appear to be a contiguous, specialized population of cells that will form the initial boundary. Ultimately, all notochord cells become boundary cells by first intercalating between one another and finally intercalating between those constituting the initial boundary (Keller et al., 1989a).

Individual cells cross the notochord-somite boundary in both directions, although this occurs infrequently. Only two cells crossed from the notochord into the somitic mesoderm in five recordings, each spanning several hours with hundreds of cells in view. For example (Fig. 7), the boundary (small white pointer, $0 \mathrm{~min}$ ) formed three cells lateral to a cell (large white pointer, $0 \mathrm{~min}$ ), placing it within the notochord, but the cell subsequently migrated laterally (20 min), crossed the boundary, and took up permanent residence in the somitic mesoderm (40 min). We observed only one cell moving from the somitic territory into the notochord, and its behavior was similar to that of cells moving in the other direction.

\section{Progression of MIB in the notochord}

After formation of the $\mathrm{VgAZ}$ and the notochordal-somitic mesodermal boundary, mediolateral intercalation behavior is expressed in a vegetal-to-animal (prospective anterior-toposterior) and a lateral-to-medial progression in the notochord (see Fig. 1, for axial directions). This progression is reflected in the elongation and alignment of cells posteriorly along the notochordal-somitic mesodermal boundary and inward (medially) from the boundary in explants that converge and extend (Figs 8, 9). Mean LWRs were determined for mediolateral and anterior-posterior sectors by morphometrics (Fig. 10A,B). The mean LWR of the lateral zone (no. 1) increases first, followed by the mean LWRs of the lateral/medial (no. 2) and the medial (no. 3) sectors (Fig. 10A). The three mediolateral zones do not differ significantly from one another at stage 12 (comparing: lat with lat $/$ med $P<0.407$, lat $/$ med with med $P<0.807$, lat with med $P<0.238$ ). At stage 13 , mean LWRs are higher in lateral sectors than those in medial sectors. The boundary cell population has a significantly higher mean LWR than the two medial cell populations $(P<0.003)$, while the lateral-medial and medial populations do not differ significantly $(P<0.511)$. By stage 14 (for simplicity, data for this stage is not plotted in Fig. 10A) and continuing to stage 16, the cell LWRs of these three cell populations no longer differ significantly $(P<0.26$ to $P<0.756)$. However, the cell LWR 

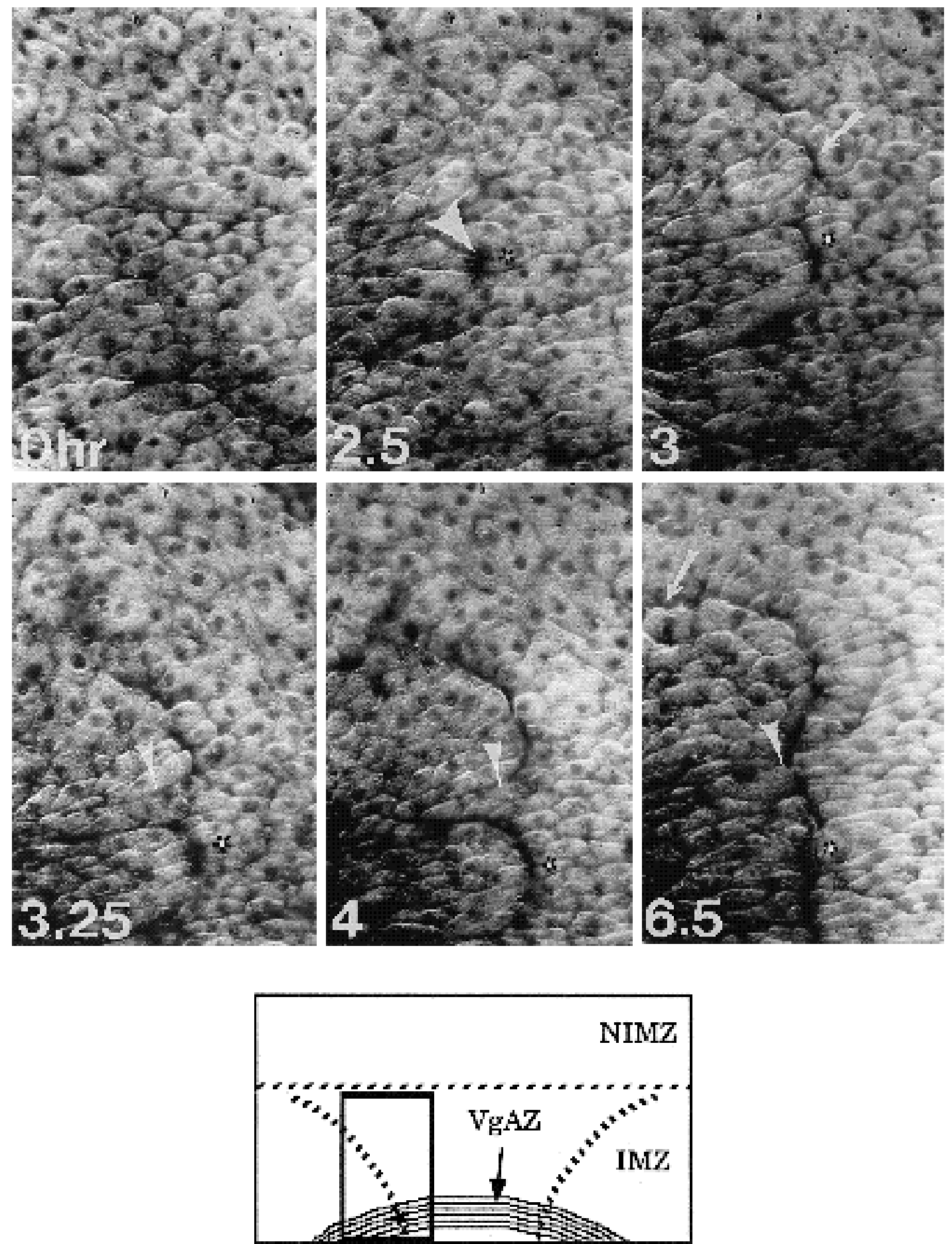

Fig. 4. A series of micrographs made from a time-lapse video recording shows the development of the notochordal-somitic boundary beginning at stage $10.5(0 \mathrm{hr})$ and thereafter at the times indicated at the lower left. The rectangle at the bottom indicates the location in the explant of the region shown in the micrographs. The $\mathrm{VgAZ}$, the future site of the notochordal-somitic boundary (dotted curved lines), the noninvoluting marginal zone (NIMZ), and involuting marginal zone (IMZ) are shown. The notochordal-somitic boundary is always initiated with the formation of a localized dark region, indicating a pit or cleft, within the $\mathrm{VgAZ}$ (white pointer, $2.5 \mathrm{hr}$ ). The corresponding location in the diagram at the bottom is indicated with an asterisk. The notochord cell medial to the initial boundary is marked in all micrographs with a white dot. The boundary progresses animally and laterally, its farthest extent indicated by white arrows. Note the tongue of notochord extending laterally into the somitic territory (small white pointer) and withdrawn from the somitic region between 3.25 and $6.5 \mathrm{hr}$ (small pointers). 


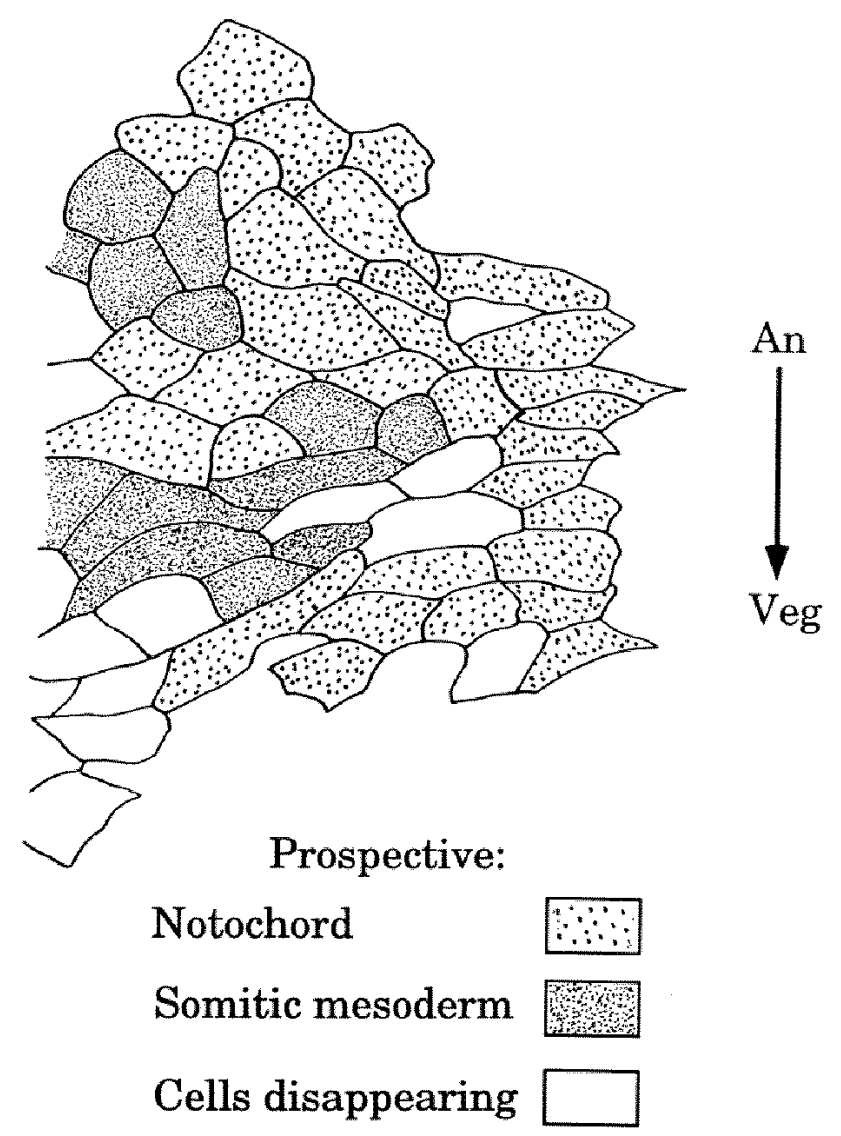

Fig. 5. The pre-boundary positions of prospective notochordal and somitic cells were traced back to stage 10.5 in time-lapse recordings. The fate of the cells disappearing in the course of the recording is not known.
Stage 10.5

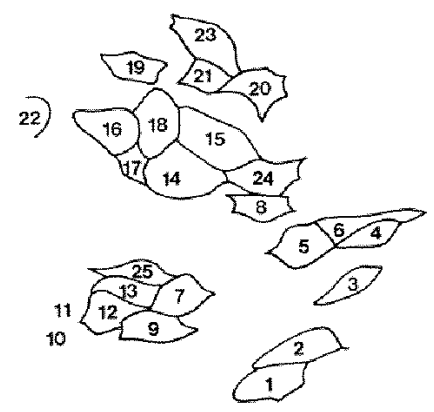

Stage 13.5

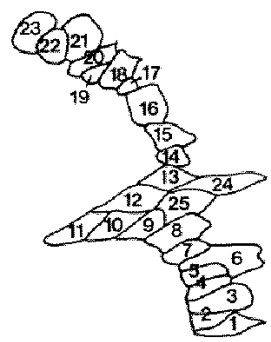

An

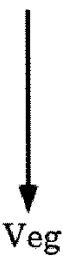

Fig. 6. The origin and movements of cells participating in the formation of the initial notochordal-somitic boundary is shown by tracing identified cells in Fig. 4 backward from stage 13.5 to stage 10.5. Note that cells 9-12 constitute the tongue of notochord cells, which is pulled out of the somitic region in the course of events shown in Fig. 4.

values of the three time points, in Students $t$-value analysis both as paired and unpaired groups, differ significantly from one another (stage 13/stage 14, $P<0.019$; stage
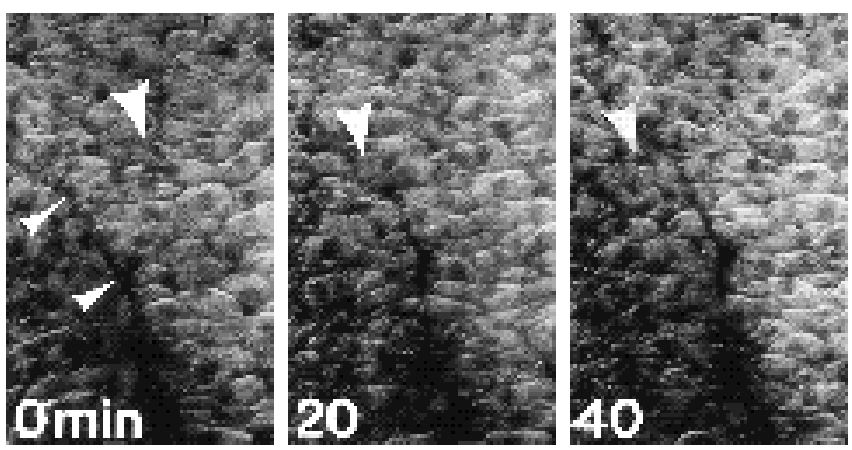

Fig. 7. A series of photographs from a time-lapse video recording shows that cells can cross the notochord-somite boundary, although they rarely do so. The cell marked with a large white pointer is initially located 3 or 4 cells into the notochord ( $0 \mathrm{~min}$ ) but subsequently moves toward the boundary, indicated by a small white pointer $(20 \mathrm{~min})$, and then across the boundary into the somitic territory (40 min), where it resides permanently as a somitic cell. Vegetal is at the bottom and animal at the top; the small white pointers indicate the notochord-somite boundary.

$14 /$ stage $16, P<0.008$; and stage $13 /$ stage $16, P<0.000$; stage 12 in comparison with stages 13,14 , and $16 P<0.000$ ).

In the vegetal-animal (prospective anterior-posterior) direction, the mean LWR is initially low everywhere except in the vegetal end of the notochord, where cells have already participated in VgAZ formation (Fig. 10B, stage 12). Thereafter, cell elongation proceeds animally or posteriorly in the notochord (stage 12-16, Fig. 10B). The mean LWR rises first in mid-body sectors (stage 13-14, Fig. 10B) and then in posterior sectors (stage 16, Fig. 10B). We compared mean LWRs of anterior-posterior zones in pairs through the four stages and found that the transition from unelongated to elongated cells moves animally (posteriorly), as revealed by significant differences between mean LWRs. At stage 12, the LWR values makes a sharp transition between zones 2 and 4 (comparing: 1 with 2, $P<0.117$; 4 with $6, P<0.117$; 1 with $4, P<0.000$ ). Subsequently, the transition moves animally, between zones 6 and 8 at stage 13 and between 8 and 10 by stage 14 . At stage 16, LWR values had risen throughout, and zones 2 through 10 no longer differed significantly from one another (minimum $P<0.27$ ) although position 1 , the most vegetal, still differ significantly from all others. These analyses show that the cells in the notochord elongate and align progressively from the vegetal end animalward (from anterior-toposterior) and at any animal-vegetal level, from lateral-tomedial.

Boundary cells in the notochord elongate perpendicular to the notochordal-somitic boundary (Figs 4, 8 and 9). Medial cells are elongated and aligned parallel to arcs across the width of the notochord, thus forming a curved pattern in which all cells are both parallel to the mediolateral axis and perpendicular to the anterior-posterior axis of the notochord (Figs 8, and 9; refer to Fig. 1 for axes). This is demonstrated by the wider notochords in explants showing little convergence and extension, as discussed below (Figs 13, 14). 

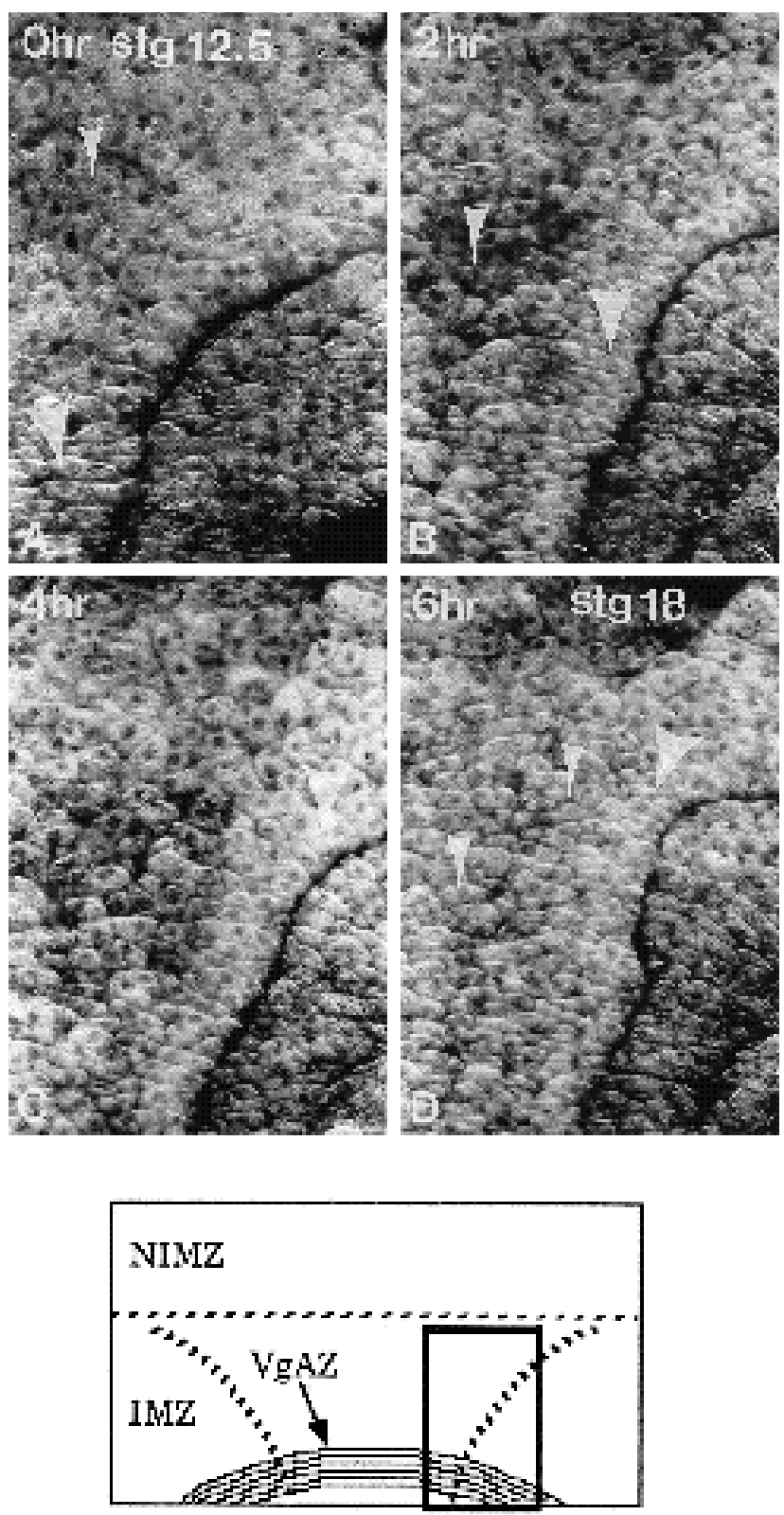

Fig. 8. A series of micrographs printed from a time-lapse recording shows the progressive elongation and alignment of the notochord cells medially from the boundary and in the vegetal-toanimal (prospective anterior-to-posterior) direction. The position of micrographs relative to the whole explant is shown by the box outlined in the diagram at the bottom, which also shows the vegetal alignment zone (VgAZ) and the notochordal-somitic boundary (dotted, curved lines). Cells in the vegetal (anterior) end of the notochord are aligned (large pointer, $0 \mathrm{hr}$ ) while those at the animal (posterior) end have not yet done so (small pointer, $0 \mathrm{hr}$, stage 12.5). Two hours later cells along the boundary in the posterior region (large pointer, $2 \mathrm{hr}$ ) are now elongated and aligned while the medial cells at the same level are less so (small pointer, $2 \mathrm{hr}$ ). After 4 hours, more medial cells are now aligned (large pointer, $4 \mathrm{hr}$ ). After 6 hours (control stage 18), anterior medial cells and all posterior lateral cells are elongated and aligned. Note that while cells at the boundary are consistently aligned perpendicular to the boundary, medial cells are aligned along arcs that lie parallel to the axis of mediolateral intercalation and perpendicular to the prospective anterior-posterior axis.
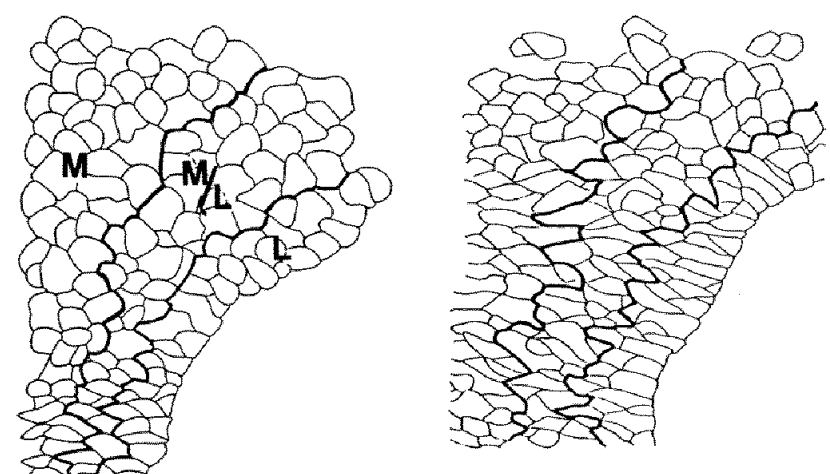

Stage 12.5

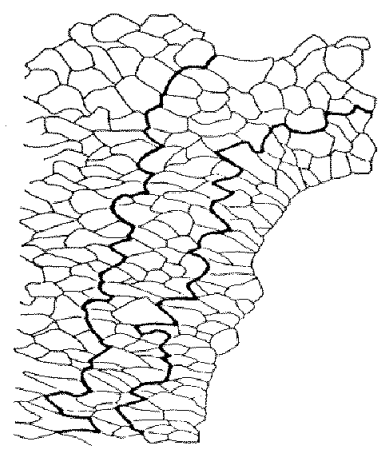

Stage 16

Stage 14

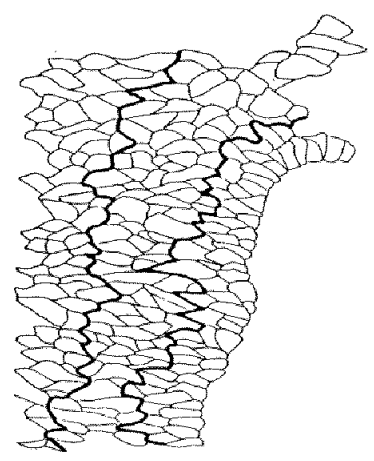

Stage 19

Fig. 9. Outlines of notochord cells were traced from time-lapse video recordings at four stages of development. The notochord is divided into medial $(\mathrm{M})$, mediolateral $(\mathrm{M} / \mathrm{L})$ and lateral $(\mathrm{L})$

regions. The LWRs of the cells in these regions are plotted in Fig. 10. Vegetal is at the bottom, animal at the top, and the left edge is the midline of the developing notochord.

\section{Protrusive activity of MIB and its modification at the notochordal-somitic boundary}

Low light fluorescence microscopy of FDX-labelled cells reveals that the cell elongation and alignment observed here, and used as an indicator of mediolateral intercalation behavior, results from the medially and laterally directed bipolar protrusive activity observed previously (Shih et al., 1992a). Cells abutting the notochordal-somitic boundary show a modified mediolateral intercalation behavior. The ends of these cells lying at the notochordal-somitic boundary or those entering this boundary become quiescent, as reported earlier (Keller et al., 1989a). Time-lapse recording of cells during boundary formation reveals that protrusive activity at the notochordal-somitic boundary differs, depending on whether the boundary forms before or after the cells express mediolateral intercalation behavior. The boundary-facing ends of the cells bleb rapidly when the boundary forms within the $\mathrm{VgAZ}$, or when internal notochordal or somitic cells intercalate into a boundary that has already formed (triangle, Fig. 11, 0 and $45 \mathrm{~min}$ ), whereas their opposite ends (the medial ends of the notochord cells and lateral ends of the somitic cells) make large filiform and lamelliform protrusions (arrows, Fig. 11, 0-135 min). Blebbing at the boundary is soon followed by quiescence (note stable boundary ends of labelled cells indicated by 

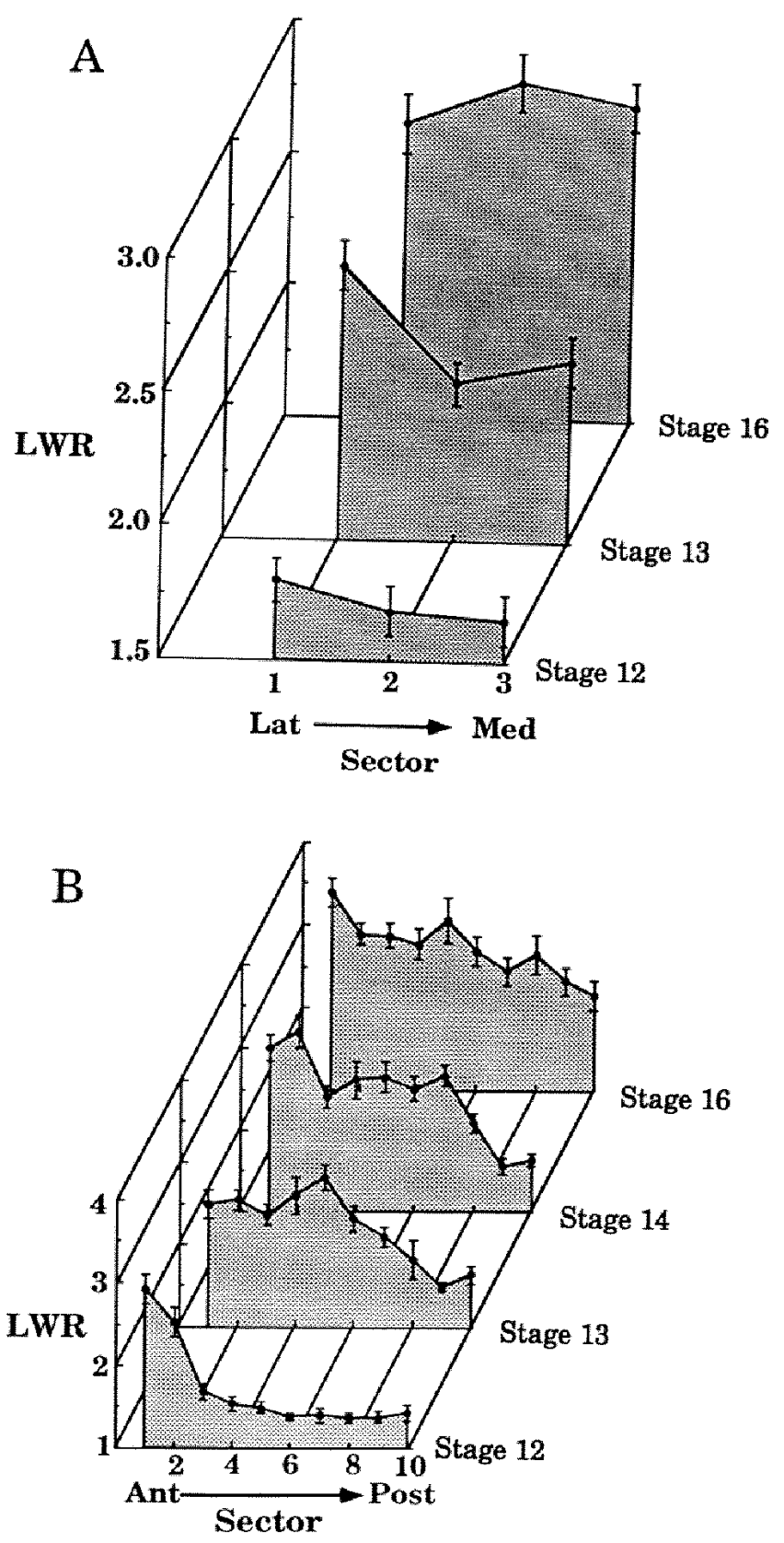

Fig. 10. Graphs (A) show that the mean LWR of notochordal cells increases in lateral-to-medial progression with developmental stage. The lateral-medial aspect of the notochord was divided into three sectors, lateral (Lat), lateromedial (Lat/Med) and medial (Med) as shown in Fig. 9. A similar series of graphs (B) shows that the mean LWR of notochord cells increases in the prospective anterior (Ant)-to-posterior (Post) direction with developmental stage. The anterior-posterior extent of the notochord was divided into 10 sectors (not shown) and the LWRs were measured from tracings of cell outlines seen in time-lapse video recordings of the explants.

white bars, Fig. 11, 90-225 min), which is associated with formation of stable filiform protrusions within the plane of the boundary (see Keller et al., 1989a). The second type of protrusive activity occurs when the boundaries form among rounded cells not yet expressing mediolateral intercalation behavior, in which case, the cells do not bleb during or after boundary formation. Instead, the boundary-facing ends of these cells remain quiescent and stabilize the boundary surface while their opposite ends show the polarized filiform/lamelliform protrusive activity associated with intercalation. In both cases, protrusive activity of the type used in cell translocation is suppressed at the boundary, and thus most but not all cells stay at the boundary. In a 2 hour period beginning in stage 13 and ending in stage 14, the total cell number making up a segment of boundary increased from 24 cells to 37 cells, an increase of 54\%, for an intercalation rate of $27 \%$ per hour. A low rate $(2 \%$ per hour) of cells leave the boundary.

\section{Progressive vacuolation of notochord cells}

The vacuolation of notochord cells in shaved explants also progresses in a vegetal-to-animal and a lateral-to-medial order (Fig. 12). This is particularly evident in explants that have not been allowed to converge and extend, as described below. Thus the histological differentiation of notochord cells follows the preceding morphogenetic progression.

\section{Progression of MIB and vacuolation of the notochord in shaved explants that do not converge and extend}

Normally the progression of MIB and vacuolation in the notochord is not easily recognized because convergence compresses the mediolateral axis. Convergence and extension can be reduced or stopped with increased coverslip pressure, presumably by increasing friction. Cells in these explants show all the protrusive activity and cell shape changes seen in normal, converging and extending explants, except that mediolateral intercalation is minimal and the elongation of the cells is exaggerated (Shih and Keller, 1992a). Tissues differentiate in place in these explants, without benefit of convergence and extension movements.

Under these conditions, the notochordal-somitic boundaries form approximately in the positions predicted by the fate map (Keller, 1976), and thus the boundaries of the two tissue territories appear to be normal, or nearly so. However, the posterior, medial tissue in the notochord territory does not differentiate, a phenomenon that also occurs in the somitic mesoderm (see below). The notochord remains very wide and the lateral and anterior cells elongate and align (white triangles, Fig. 13A), whereas those in the corresponding medial, posterior region do not (large black pointer, Fig. 13A). Cell elongation and alignment do occur in the original, narrow $\mathrm{VgAZ}$ (black arrows, Fig. 13A). Subsequently, in the tailbud stages, cells vacuolate in the lateral regions, next to the notochord boundary (white pointers, Fig. 13B), and across the original VgAZ (large pointers, Fig. 13B) but not in the posterior, medial region of the notochord (large pointers, Fig. 13B).

\section{MIB and tissue differentiation proceed from anterior-to- posterior and from lateral-to-medial directions in the somitic mesoderm}

The progression of mediolateral intercalation behavior and tissue differentiation in the somitic mesoderm parallels their 

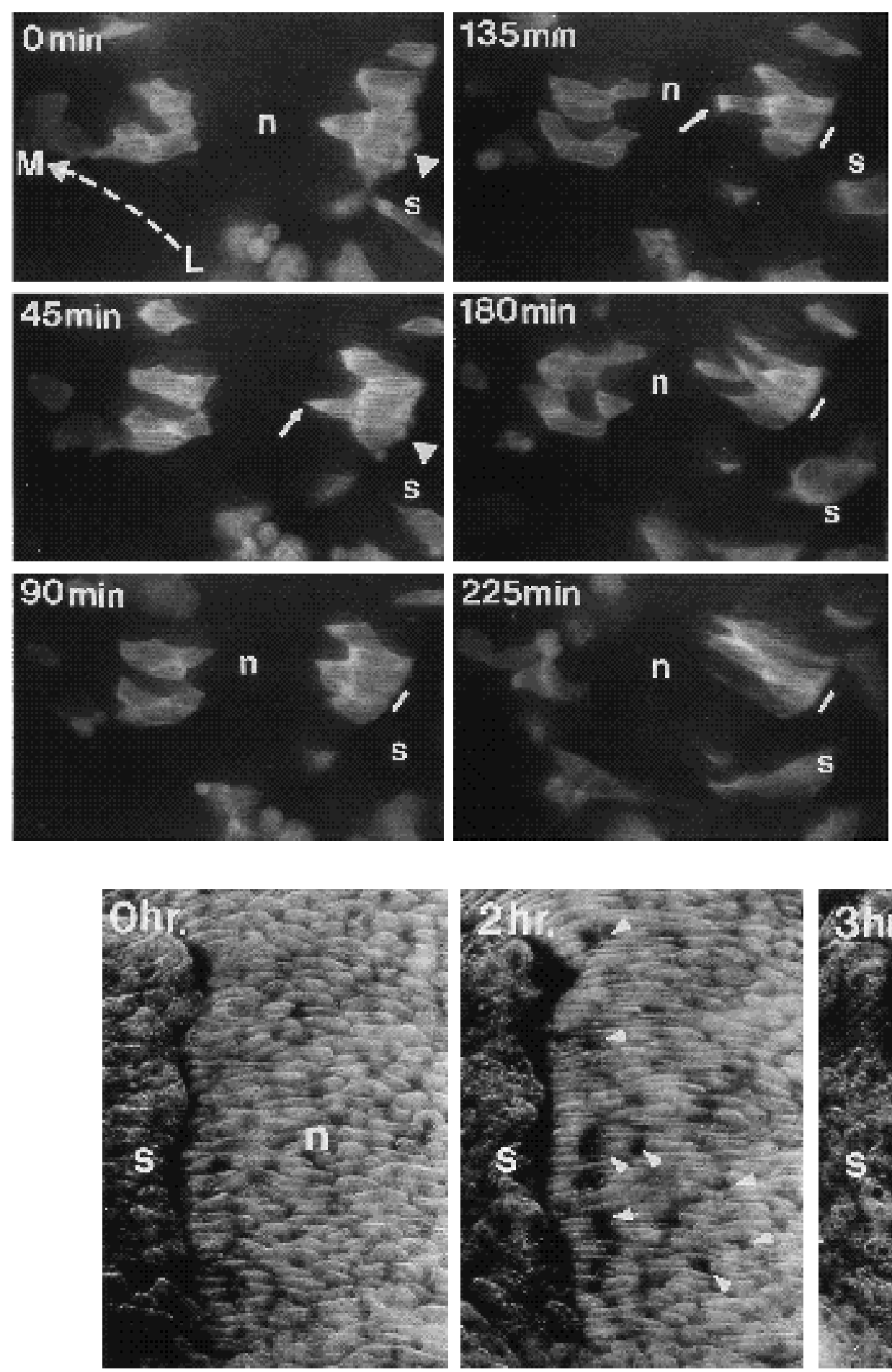

Fig. 11. Low light, time-lapse fluorescence microscopy of FDXlabelled cells shows the protrusive activity of elongating, aligning and intercalating mesodermal cells. The lateral (L)-to-medial (M) axis is indicated by the curved, dashed arrow and the vegetal (or anterior)to-animal (posterior) axis is perpendicular to the lateral-medial with the vegetal end at the lower left. Notochord (n) and somitic (s) territories are included, with the boundary forming at the white triangles ( 0 and $45 \mathrm{~min}$ ) and indicated thereafter by a white bar. The progressive elongation and alignment of notochord cells are associated with the progressive restriction of protrusive activity to the medial and lateral ends of the cells, such that they elongate and align in arcs parallel to the mediolateral axis (0-90 min). Elongated and aligned notochord cells entering the notochord-somite boundary bleb at their boundary ends (triangles, 0 and $45 \mathrm{~min}$ ), whereas their medial ends form migratory lamelliform or filiform protrusions (arrows, 45, 90 and $135 \mathrm{~min}$ ). Later the boundary ends cease all protrusive activity and become monopolar (white bars, 90-225 min).

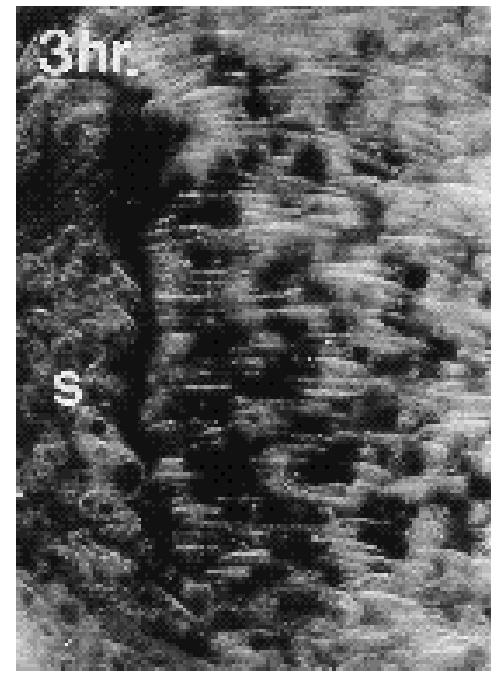

Fig. 12. Video frames taken from time-lapse recordings show that vacuolation proceeds in a vegetal-to-animal (anterior-to-posterior) and lateral-to-medial progression within the notochord, repeating the preceding progression of cell elongation and alignment. Vegetal is at the bottom and animal at the top; the right edge is the midline of the notochord (n) and the somitic mesoderm (s) is to the left. Prior to vacuolation $(0 \mathrm{hr})$ the notochord cells are elongated and aligned. 2 hours later, at stage 26 in explants, the vacuoles are large enough to be seen clearly along the lateral boundary and at the anterior end (pointers, $2 \mathrm{hr}$ ). An hour later, vacuolation has proceeded posteriorly and medially until only the posterior medial cells remain unvacuolated (pointer, $3 \mathrm{hr}$ ).

progression in the notochord, proceeding from anterior to posterior and from lateral to medial (Fig. 14A). The anterior-posterior axis of the somitic mesoderm forms an arc, which originates just lateral to the anterior notochord and passes laterally, and ventrally (see Fig. 1 and Keller et al., 1989a). The lateral edge of the somitic mesoderm lies next 

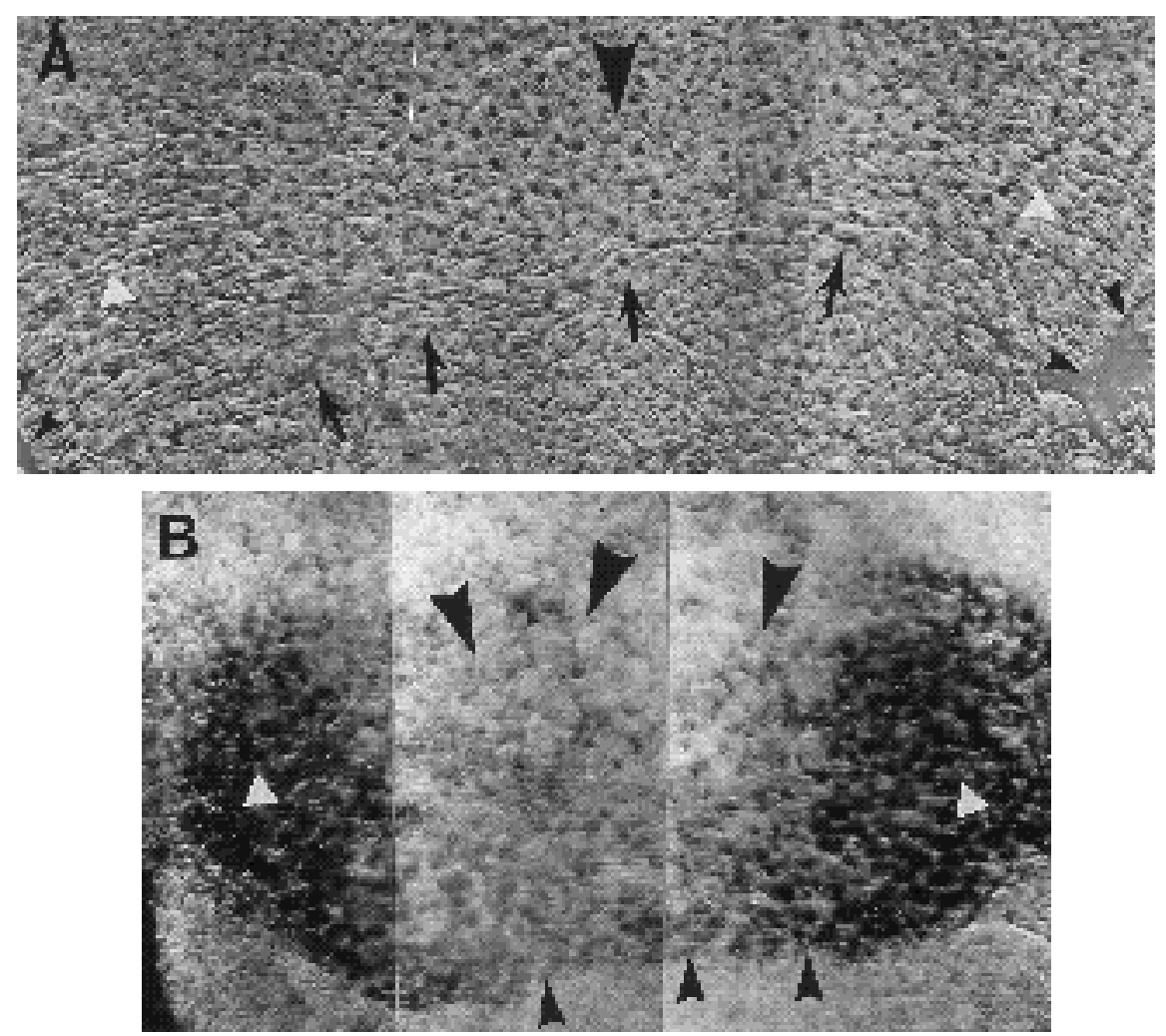

Fig. 13. The propagation of the lateralto-medial cell elongation and alignment and vacuolation of notochord cells is dramatically truncated in an explant in which convergence and extension has been suppressed with excess coverslip pressure, such that the notochord develops without changing shape. At stage 17 (A), the VgAZ (just above the small black arrows, center) forms an arc from the notochordal-somitic boundaries (indicated by small black pointers, far left and far right), across the midline of the explant. Bilateral fields of prospective lateral, anterior notochord cells, indicated by the white triangles, have elongated and aligned inward from the boundaries. This behavior has not spread to the still rounded medial cells of the same anterior-posterior level (large black pointer). Normally the entire notochord would be reduced by mediolateral intercalation to less than two cells widths by this stage and all cells would be elongated and aligned. After stage 26 (B), the pattern of vacuolation mimics the preceding pattern of elongation and alignment, with heavily vacuolated cells appearing near the vegetal end of the notochord in the original $\mathrm{VgAZ}$ (just above the small

black pointers), and along the boundaries (beneath the white triangles). However, the medial, animal (medial posterior) cells, which did not elongate and align at earlier stages, also do not vacuolate (black pointers). The cells anterior to (below) the VgAZ in both illustrations are prechordal mesoderm cells included at the vegetal end of the axial mesoderm.

to the vegetal boundary of the explant and medial edge is next to the notochord (see Fig. 1 and Keller et al., 1991a).

Cell elongation, indicating expression of MIB, occurs first in the prospective anterior somitic mesoderm (no. 2, Fig. 14A) and then the prospective anterior notochordal mesoderm (no. 1, Fig. 14A) during formation of the $\mathrm{VgAZ}$. Mediolateral intercalation behavior progresses posteriorly along the lateral margin of the somitic mesoderm (no. 2, no. 3, Fig. 14A), and from there, spreads medially toward the notochord. This medial progression is illustrated by the greater expression of mediolateral intercalation behavior laterally (no. 3) than in the corresponding medial region (no. 4, Fig. 14A). The cells of the next arc, representing a slightly more posterior level, show no elongation or alignment (no. 5, Fig. 14A). Cell outlines and mean LWRs show that MIB is initiated at the anterior, lateral margin and progresses posteriorly along the lateral margin (Fig. 15). At given anterior-posterior level, cell elongation and alignment progress in arcs, beginning laterally and proceeding medially, toward the notochord (Fig. 15).

\section{Segmentation and further differentiation of the somitic mesoderm proceeds from lateral to medial and from anterior to posterior}

Segmentation of somitic mesoderm becomes visible in shaved explants at stage 16 . The anterior intersomitic fis- sures form rapidly and follow the preceding pattern of MIB. They progress from the prospective anterior to posterior (no. 1-no. 5, Fig. 14B) and from the lateral margin of the somite (the vegetal edge of the explant) towards the prospective medial edge (the notochord-somite boundary; white arrows, Fig. 14B). Differentiation of somitic mesoderm, as seen by staining with the 12-101 antibody, shows the same anterior-posterior and lateral-medial progression (Fig. 16). As in the notochord, when little or no convergence and extension occurs, the mediolateral axis of the somitic mesoderm remains relatively long. The markers of somitic differentiation, cell elongation and alignment, intersomitic furrows, and 12-101 staining of the somitic mesoderm, fail to proceed medially far enough to reach the notochord except in the narrow anterior region.

\section{Correlation with cell shapes in vivo}

In previous work, we described the bipolar, mediolaterally elongated cells, bearing large medial and lateral protrusions, in the postinvolution dorsal mesoderm (Keller, 1984) and just outside the dorsal lip of the blastopore (Keller et al., 1989b). We speculated that this morphology was involved in mediolateral intercalation, a speculation subsequently supported by indirect evidence that mediolateral intercalation of mesodermal cells is primarily a postinvolution behavior (Keller and Tibbetts, 1989; Wilson and Keller, 1991). To reaffirm where the characteristic elongate, 


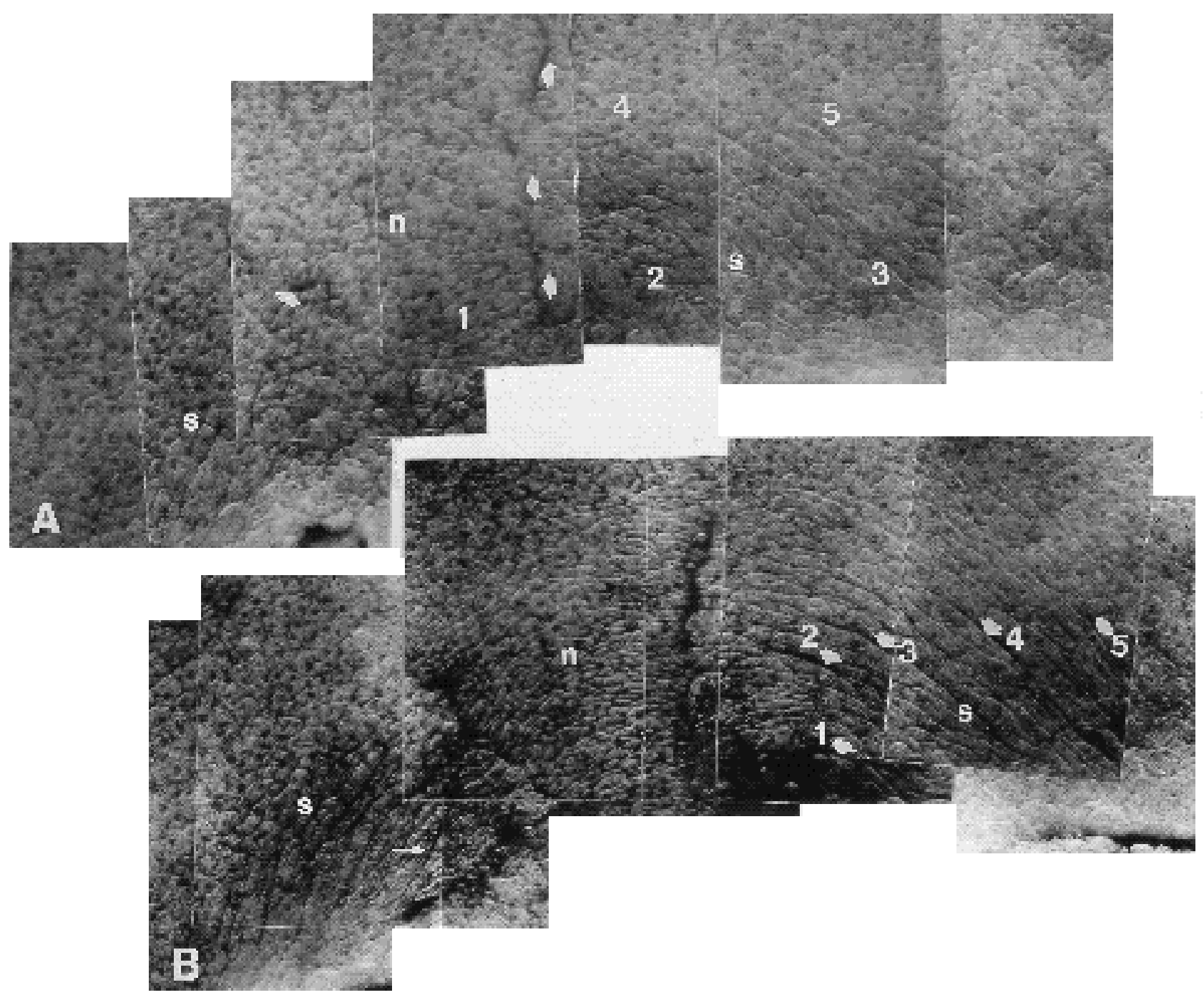

Fig. 14. Large, shaved explants of a large part of the DMZ near the dorsal midline, show that cell elongation and alignment proceed in the vegetal-to-animal (anterior-posterior) and lateral-to-medial direction in the somitic mesoderm, as in the notochord. At stage 11.5-12 (A), the notochord-somite boundaries (white pointers) are already well defined, and the vegetal (prospective anterior) regions of the notochord (site no. 1, A) and somitic mesoderm (site no. 2, A) have already aligned. However, at more posterior levels of the somitic mesoderm, cell elongation and alignment has occurred only at the vegetal edge of the explant (the prospective lateral edges of the somites), as shown at site no. 3 (A), but not at the corresponding medial region of somitic mesoderm, next to the notochord, at this anterior-posterior level (site no. 4, A). By stage 18 (B), five intersomitic (segmental) furrows are clearly visible (white pointers, B). Time-lapse recordings show that they begin forming at the lateral edge (next to the vegetal endoderm) and proceed medially. They also form from prospective anterior-toposterior (no. 1 through no. 5). Thus, the furrows formed earliest are longer and have reached the notochord boundary (no. 1-no. 2) while the ones formed later have not reached the notochord-somite boundary (no. 3-5). n, notochord; s, somitic mesoderm.

aligned cells reside during gastrulation, we measured the LWRs in SEMs of selected regions. Animal cap ectodermal cells and preinvolution mesodermal cells are approximately isodiametric (Fig. 17, column 1) and remain so throughout gastrulation (data not shown; see Keller, 1980). Cells just beginning to involute over the blastopore lip at stage 10.5 have a slightly greater length-width ratio (Fig. 17, column 2). In subsequent stages, the deep cells immediately beneath the endodermal epithelium and the deeper mesodermal cells at the blastoporal lip and in the postinvolution mesoderm become progressively more elongate, with LWRs averaging from 2.5 to just over 3.0 by stage 11.5 (Fig. 17, columns 3-7).

\section{Discussion}

Patterns of cell motility underlying convergence and extension of the notochordal and somitic mesoderm

MIB drives convergence and extension but, in turn, is modified by convergence and extension. Thus we will summarize the expression of MIB in explants that converge and extend and those that do not. The pattern of expression of MIB in explants that are not allowed to converge and extend is shown diagramatically (Fig. 18A). (1) After the cells divide once between stage 10 and 10.5, MIB begins laterally and progresses medially to form the arc-shaped $\mathrm{VgAZ}$, which includes the prospective anterior notochordal and 

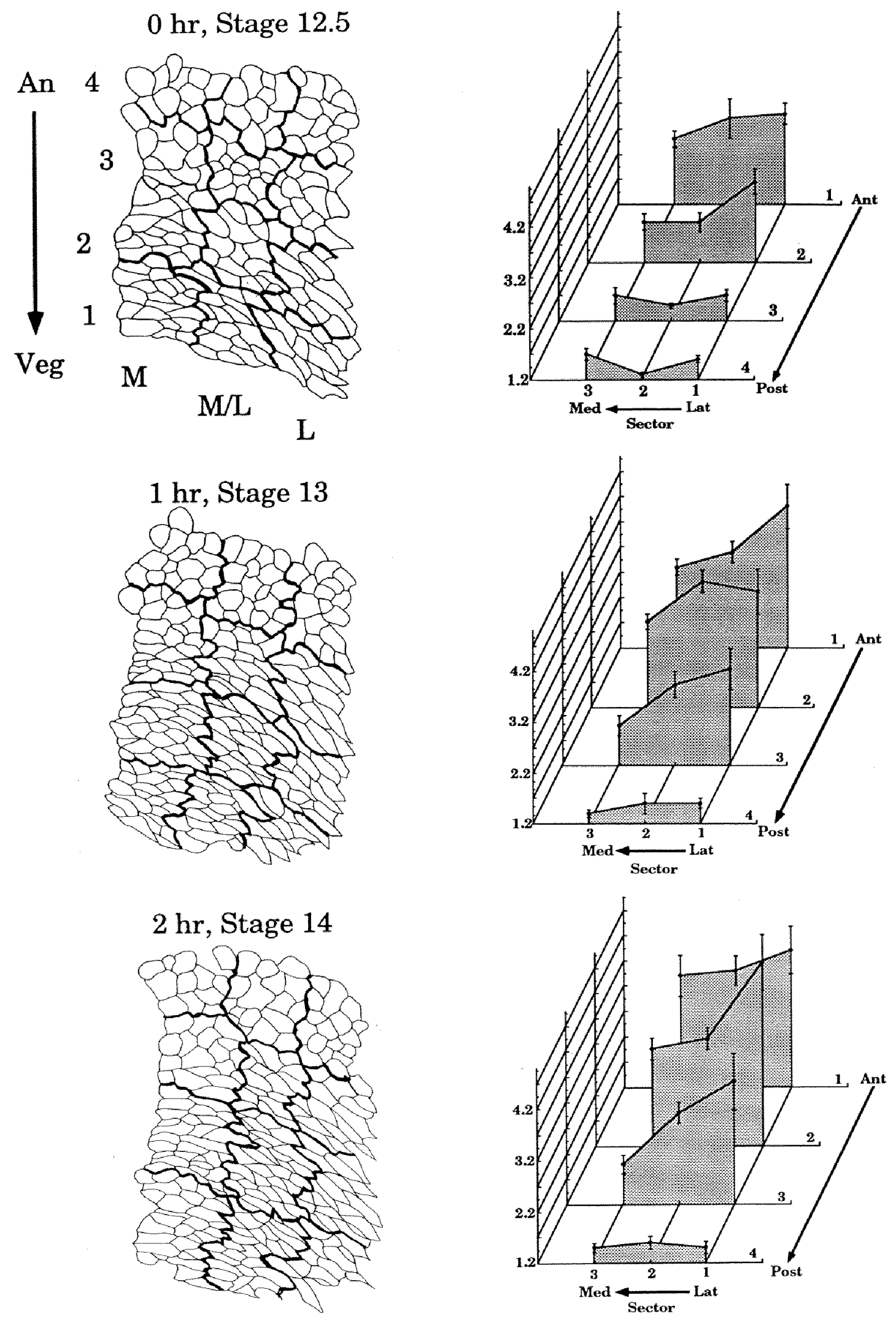

Fig. 15. Tracings of cells of the somitic mesoderm at stages 10.5, 11 and 12 (A) show the progressive vegetal-to-animal and lateral-tomedial progression of cell elongation and alignment. The somitic mesoderm was divided into four anterior-to-posterior sectors (no. 1 through no. 4, respectively) and three mediolateral sectors (M, medial, M/L, mediolateral, L, lateral). Graphs of the LWRs of cells in these sectors (B) show the progressive increase in mean LWR in anterior (Ant)-to-posterior (Post) sectors and in the lateral-to-medial sectors $(\mathrm{L}, \mathrm{M} / \mathrm{L}, \mathrm{M})$ with developmental stage. 


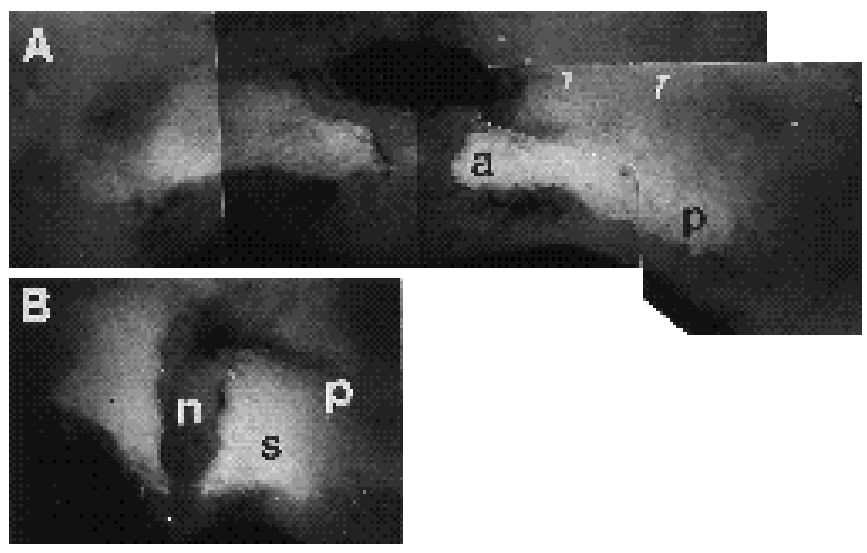

Fig. 16. Staining of the somitic mesoderm of an open-faced shaved explant with the 12-101 monoclonal antibody shows the anterior-posterior and lateral-medial progression of somite differentiation. In explants that have not been allowed to extend (A), staining is strong across the lateral edge of the somitic mesoderm, next to the vegetal endoderm, from anterior (a) to posterior ( $\mathrm{p}$ ), but fades out medially (pointers). In explants that have been allowed to extend more (B), the somitic mesoderm (s) stains strongly all along its mediolateral axis to the notochord (n) but the stain fades posteriorly (p). The diagrams at the lower right indicate the principal axes and tissues in each explant and the differences in movements in each (arrows); for details see Keller and others, $1991 \mathrm{~b}$

somitic tissue at the vegetal end of the explant (Fig. 18A, stage 10.5-10.75). In these explants, MIB results in cell elongation and alignment but no intercalation of the type

Fig. 18. Schematic diagrams show the progression of mediolateral intercalation behavior across the shaved explants of the marginal zone of Xenopus, which were not (A) and were (B) allowed to converge and extend. The expression of MIB is indicated by elongated, aligned, red outlines of cells. The notochordal-somitic boundary (dashed arrows), the notochordal (n), and the somitic (s) territories are shown. Within the explants, the open arrows indicate the progress of MIB in the anterior-posterior direction and the solid arrows indicate progress of MIB in the lateral-medial direction (see the text). Outside the explant, the solid arrows indicate convergence and extension movements. A vegetal view of the midgastrula (C) shows MIB expression progressing posteriorly just outside the blastoporal lip (open arrows), where convergence or constrictive forces tend to roll the lip downward and over the lip (solid arrows) (see text for a description). The lines along which convergence or constrictive forces are generated by the progression of MIB are represented by red arcs (D). The explant is depicted as if the vegetal endoderm (green, D) was not removed; each arc originates laterally and is normally anchored laterally near the vegetal endoderm. The role of the posterior progression of constrictive forces in generating involution is illustrated schematically by the shortening of the red arcs (E). Note that the separated arcs are used only for illustration; normally the progression is spatially continuous rather than in the form of discrete, separated arcs. Also, the mesoderm is normally covered by the suprablastoporal endodermal epithelium. Only anteriorly do the notochordal and somitic components of the arcs stay in register; posteriorly the notochord shears posteriorly along the medial boundary of the somitic mesoderm (see Keller et al., 1991b, Fig. 5, for an explantation of this geometry), but the tissues maintain mechanical continuity at their boundaries.

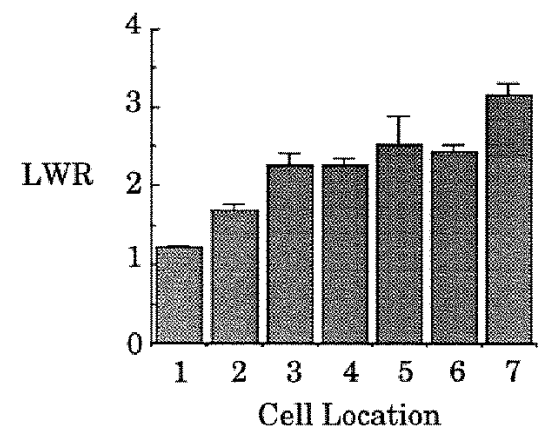

Fig. 17. The mean length/width ratios of deep cells in embryos were measured from scanning electron micrographs. Mesodermal cells are referred to as 'deep' if they are away from the epithelium and 'shallow' if they lie immediately beneath the epithelium. The columns represent: (1) animal cap ectodermal cells, stage 10; (2) shallow mesoderm at blastoporal lip, stage 10.5; (3) shallow mesoderm at blastoporal lip, stage 10.75-11: (4) postinvolution deep mesoderm, stage 11 (5) postinvolution deep mesoderm, stage 11+: (6) shallow mesoderm at blastoporal lip, stage 11: (7) postinvolution deep mesoderm, stage 11.5.

that produces convergence and extension. (2) The notochordal-somite boundaries are initiated in the lateral parts of the $\mathrm{VgAZ}$ at the midgastrula stage (Fig. 18, stage 11). (3) The notochordal-somitic boundaries arc animally and laterally in the prospective posterior direction during gastrulation, outlining the notochord as it appears in the fate map (Fig. 18A, stage 11+) (cf. Keller, 1976). (4) Notochordal cell elongation and alignment proceed posteriorly from the $\mathrm{VgAZ}$, along the notochord-somite boundaries (open, curved arrows, Fig. 18A, stage 11+). (5) At the same time, somitic cell elongation and alignment proceed laterally around the marginal zone, in the prospective posterior direction, from the $\mathrm{VgAZ}$, along the lateral boundary of the somitic mesoderm (open, straight arrows, Fig. 18A, stage 11+). (6) In both somitic and notochordal mesoderm, cell elongation and alignment also proceed medially from their respective lateral boundaries, toward the midline in the case of the notochord, and toward the notochord in the case of the somitic mesoderm (solid arrows, Fig. 18A, stage 11+). (7) Vacuolation of notochord cells proceeds medially from the boundaries of the notochord and progresses from anterior to posterior (not illustrated). (8) Segmentation proceeds from anterior to posterior within the somitic mesoderm, the intersomitic furrows beginning at the lateral margins and proceeding medially (not illustrated). When convergence and extension are not allowed to occur, tissue at the posterior medial regions of both notochordal and somitic territories (asterisks, Fig. 18A, stage 11+) do not undergo cell elongation and alignment, and they do not differentiate.

When less mechanical resistance is imposed, MIB results in mediolateral intercalation, and convergence and extension occur (Fig. 18B). In this case, MIB and tissue differentiation occur to the midline of the notochord and to the medial region of the somitic mesoderm (Fig. 18B, stage $10.75-11+)$. Our hypothesis is that MIB is organised medially from the lateral boundaries of both the somitic and notochordal mesoderm, these being the sources of the organizing signals. Thus in converging explants the signals 
organizing MIB (and tissue differentiation) are made more effective as MIB brings medial prospective notochordal and somitic cells within their range, whereas in nonconverging explants these cells never fall within range of the signals (cf. Fig. 18A,B). The lateral-to-medial progression of segmental furrows is also seen in the embryo and in openfaced explants (see Wilson et al., 1989; Wilson and Keller, 1991). The arc-shaped pattern of posterior progression encompasses the entire notochord region and the first six or seven somites relatively fast and early, making the anterior-posterior timing difference less obvious, but the posterior progression continues for a longer time in the posterior somitic mesoderm, as this mesoderm moves around the blastopore and comes to lie along both sides of the notochord during neurulation (see Wilson et al., 1989; Keller et al., 1989a, 1991a).

\section{Significance of progressive MIB in patterning the chordamesoderm}

The progress of mesodermal cell behavior and tissue differentiation from lateral to medial and from anterior to posterior in both somitic and notochordal tissue may reflect the order in which the cells were instructed to adopt these phenotypes, and thus may reflect the geometry of the signals that instruct them. This turns our attention to the lateral boundaries of the somitic and notochordal mesoderm as possible sources of organizing signals. Both tissues develop medially from the lateral boundaries, and medial, posterior cells of both notochordal and somitic territories do not differentiate in the absence of convergence. This suggests that morphogenetic and histological differentiation requires convergence of the signal-generating boundaries towards the medial cells in order for these cells to respond. If progress of the cell behaviors and differentiation reflects the order of commitment, then the posterior, medial cells within both notochordal and somitic territories should be the last committed to a behavior or tissue phenotype. Likewise, if organizing signals are proceeding inward from the boundaries, competent cells grafted into notochordal or somitic fields should express MIB and tissue differentiation in a pattern reflecting this progresion. We are testing this by relocating cells within shaved explants and monitoring their behavior and differentiation. Animal cap cells grafted into central notochord region at the early gastrula adopt MIB and form notochord from anterior to posterior (C. Domingo, personal communication; see Keller et al., 1992c), as if they were exposed to a notochord-organizing signal in this same order.

It is not clear how the signals from vegetal endoderm (the sub-blastoporal endoderm) that function in the induction and patterning of mesoderm (Nieuwkoop, 1969a,b; Sudarwati and Nieuwkoop, 1971) generate the highly organized patterns revealed above, nor is it clear how these patterns are related to the three-signal model of mesoderm organization (Dale and Slack, 1987) or to the current thinking about how growth factors possibly involved in mesoderm induction generate fate maps (see Green and Smith, 1992; Cooke et al. 1987; Slack et al., 1987; Smith et al., 1988; Kimelman et al., 1988; Cooke, 1991). The progression of cell behaviors described here may reflect the final sequence of events in determining cell behavior and phenotype rather than earlier steps in organizer differentiation (see Gerhart et al., 1991; Cooke, 1991). The idea that commitment of cells to specific behaviors and tissue identities may still be going on progressively in the dorsal mesoderm during gastrulation is consistent with the organizer activity of this region when grafted to other sites (Spemann, 1938; Gimlich and Cooke, 1983). Moreover, it is perhaps no surprise that the organizer patterns cell behaviors in a highly ordered progression, since such a progression may be essential for proper involution movements during gastrulation (see below).

\section{Relation of the notochordal-somitic boundaries to patterning}

Boundary formation seems to be superimposed on the mesodermal cells independent of their motility. The anterior notochordal-somitic boundaries form among cells that are in the midst of MIB, whereas the posterior boundaries form among cells not yet showing this behavior. These two cell populations respond differently to the boundaries. Anterior cells already undergoing mediolateral intercalation bleb wildly at their site of contact with the boundary, both when the boundary forms among them and when they contact the boundary after it forms; only later are protrusions stabilized on the boundary, making the cells monopolar (see Keller et al., 1989a; Weliky et al., 1992). In contrast, when the boundary forms among the posterior cells not yet expressing MIB, they do not bleb. When they do begin MIB, they immediately stabilize their protrusions on the boundary. Moreover, the boundaries appear to be directional sources of signals, resulting in different behaviors and states of cell commitment on their notochordal and somitic sides. Cells on the notochordal side express mediolateral intercalation behavior and are perhaps committed to notochordal fates, while cells at the same level but on the somitic side will not express this behavior for some time and are perhaps pluripotent and uncommitted. Finally, the notochordalsomitic boundaries form in about the right positions, whether or not convergence and extension occur, and thus, unlike MIB, they appear to be relatively independent of changes in tissue dimensions.

\section{Morphogenetic significance: posteriorly progressing arcs of constriction drive involution}

The distribution of elongated cells in embryos, which reflect expression of MIB, show that MIB is initiated in the postinvolution position and progresses posteriorly, producing arcs of constriction that press on the inner surface of the IMZ, and act to roll the IMZ over the blastoporal lip (Fig. 18C). As noted here (Fig. 17) and some time ago (Keller, 1984; Keller et al., 1989b), cells of the involuted dorsal mesoderm and those cells just outside the blastoporal lip, which are about to undergo involution, are elongated mediolaterally and aligned parallel to one another, to the mediolateral axis, and to the margin of the blastopore from stage 10.5 onward. The biomechanical consequence of progressive posteriad expression of MIB can be visualized as the progressive shortening of a series of arcs that span the the IMZ and end laterally where the somitic mesoderm is anchored next to the vegetal endoderm; Fig. 18D shows an extending explant as if the vegetal endoderm were still present. In the explant, where these arcs are no longer anchored, 
their shortening results in pulling the lateral margins toward the midline, as shown in Fig. 18B. In the embryo, where these arcs are anchored near the vegetal endoderm, their progressive shortening by MIB in a progressive anterior-toposterior order rolls the IMZ over the lip (involution) and at the same time extends the IMZ in the postinvolution position (Fig. 18E). Thus convergence, extension and involution all result from the mechanics of shortening of these arcs in the spherical geometry of the embryo (Fig. 18E). This explains why convergence and extension of the involuted IMZ (see Keller et al., 1985a,b; Keller and Jansa, 1992). The continuity of these arcs is essential; if they are interrupted in the dorsolateral regions, involution fails, the notochord extends outward, and the somitic mesoderm extends and differentiates along both sides of an open blastopore, as shown in Fig. 18C (see Schechtman, 1942; Keller, 1981, 1984). Note that mediolateral intercalation in Xenopus involves shortening of mechanically continuous arcs by local cell traction, which pulls all dorsal tissue closer to the lateral anchorage points near the vegetal endoderm rather than directed cell migration toward the dorsal midline. Thus 'convergence' is a property with an axial (mediolateral) orientation, but there is no evidence at this time that it has a direction. Convergence is 'dorsal' only in that it occurs in dorsal tissue; it is not directed dorsally, based on the evidence uncovered thus far.

\section{Mediolateral cell intercalation and boundary formation}

Since mediolateral intercalation is underway when the anterior notochordal-somitic boundaries form, cells are moving across the path of the boundary as it forms. Nevertheless, the prospective notochord cell population is contiguous, for the most part, at the beginning of gastrulation. Thus differentiation of cell affinities (Holtfreter, 1939), or some other mechanism that blocks cell mixing, would have to follow very quickly on the heels of commitment of cells to one tissue or another. Otherwise, the incipient or ongoing mediolateral intercalation would move cells out of range of their homotyic neighbors. Alternatively, some mixing might occur but misplaced cells would be called back across the boundary to their own territory. The rarity of cells crossing the boundary suggests that this is not a major factor. There is no contiguous subset of specialized boundary cells; prospective initial boundary cells are distributed throughout the notochord in the early gastrula in no definable, consistent pattern. Any cell entering the boundary region changes its behavior to correspond to that of other boundary cells, and eventually all notochord cells become boundary cells (Keller et al., 1989a). This suggests that boundary formation is the response of cells to a local condition, generated by a subset of cells that happen to be in the boundary-forming region at a specific time. This local condition then modifies the behavior of internal notochord cells as they intercalate into the boundary, transforming the bipolar mediolateral intercalation behavior (Shih and Keller, 1992a) into a monopolar one (Keller et al., 1989a).

This work was supported by NSF grant DCB89052 and NIH grant HD25594. We thank J. P. Trinkaus for his inspiration, his encouragement, and his pioneering work on the study of motility in embryos. We also thank Paul Wilson for his pointed criticism and support. Finally, we thank Jessica Bolker, Dr John Gerhart, Mary Constance Lane, Nan Ho, Susan Purcell, and Amy Sater for their insightful comments and suggestions.

\section{References}

Cooke, J. (1972). Properties of the primary organization field in the embryo of Xenopus laevis. I. Autonomy of cell behavior at the site of initial organizer formation. J. Embryol. Exp. Morph. 28, 13-26.

Cooke, J. (1973). Properties of the primary organization field in the embryo of Xenopus laevis. IV Pattern formation and regulation following early inhibition of mitosis. J. Embryol. Exp. Morph. 30, 49-62

Cooke, J. (1975). Local autonomy of gastrulation movements after dorsal lip removal in two anuran amphibians. J. Embryol. Exp. Morph. 33, 147157.

Cooke, J., Smith, J. C., Smith, E. J. and Yaqoob, M. (1987). The organization of mesodermal pattern in Xenopuslaevis: experiments using a Xenopus mesoderm-inducing factor. Development 101, 893-908.

Cooke, J. (1985). The system specifying body position in the early development of Xenopus, and its response to perturbations. J. Embryol. Exp. Morph 89 Supplement, 69-87.

Cooke, J. (1989). Xenopus mesoderm induction: evidence for early size control and partial autonomous by onset of gastrulation. Development 106, $519-529$.

Cooke, J. (1991). The arrangement of early inductive signals in relation to gastrulation: results from frog and chick. In Gastrulation: Movements, Patterns, and Molecules. (ed. R. Keller, W. Clark and F. Griffin), pp. 7999. New York: Plenum Press.

Cooke, J. and Smith, J. C. (1989). Gastrulation and larval pattern in Xenopus after blastocoelic injection of a Xenopus-derived inducing factor: experiments testing models for thenormal organization of mesoderm. Dev. Biol. 131, 383-400.

Dale, L. and Slack, J. M. W. (1987). Regional specification within the mesoderm of early embryos of Xenopus laevis. Development 100, 279295.

Gerhart, J., Doniach, T. and Stewart, R. (1991). Organizing The Xenopus Organizer. In Gastrulation: Movements, Patterns, and Molecules. (ed. R. Keller, W. Clark and F. Griffin), pp. 57-77. New York: Plenum Press.

Gimlich, R. L. and Braun, J. (1985). Improved flourescent compounds for tracing cell lineage. Dev. Biol. 109, 509-514.

Hamilton, L. (1969). The formation of somites in Xenopus laevis. J. Embryol. Exp. Morph. 22, 253-264.

Holtfreter, J. (1933a). Nicht typische Gestaltungsbewegungen, sondern Induktionsvorgänge bedingen die medullare Entwickung von Gastrulaektoderm. WilhelmRoux' Arch. EntwMech.Org. 127, 591-618.

Holtfreter, J. (1933b). Der Einfluss von Wirtsalter und verschiedenen Organbezirken auf die Differenzierung von angelagertem Gastrulaektoderm. Wilhem Roux' Arch. EntwMech.Org. 127, 620-775.

Holtfreter, J. (1933c) Die totale Exogastrulation, eine Selbstablösung des Ektoderms vom Entomesoderm. Wilhelm Roux' Arch. EntwMech. Org. 129, 669-793.

Holtfreter, J. (1933d). Organisierungsstufen nach regionaler Kombination von Entomesoderm mit Ektoderm. Biol. Zentrbl. 53, 404-431.

Holtfreter, J. (1939) Gewebeaffinitat, ein Mittel der embryonalen Formbildung. Arch. Exp. Zellforsch. Besonders Geweb. 23, 169-209

Holtfreter, J. (1943a). Properties and functions of the surface coat in amphibian embryos. J. Exp. Zool. 93, 251-323.

Holtfreter, J. (1943b). A study of the mechanics of gastrulation. Part I. $J$. Exp. Zool. 94, 261-318.

Holtfreter, J. (1944). A study of the mechanics of gastrulation. Part II. $J$. Exp. Zool. 95, 171-212.

Keller, R. E. (1976). Vital dye mapping of the gastrula and neurula of Xenopus laevis. II. Prospective areas and morphogenetic movements of the deep layer. Dev. Biol. 51, 118-137.

Keller, R. E. (1980). The cellular basis of epiboly: An SEM study of deepcell rearrangement during gastrulation in Xenopus laevis. J. Embryol. Exp. Morph. 60, 201-234.

Keller, R. E.(1981). An experimental analysis of the role of bottle cells and the deep marginal zone in gastrulation of Xenopus laevis. J. Exp. Zool. 216, 81-101.

Keller, R. E. (1984). The cellular basis of gastrulation in Xenopus laevis: active post-involution convergence and extension by mediolateral interdigitation. Am. Zool. 24, 589-603. 
Keller, R. E. (1986). The cellular basis of amphibian gastrulation. In Developmental Biology: A Comprehensive Synthesis. Vol. 2. The Cellular Basis of Morphogenesis. (ed. L. Browder) New York: Plenum Press.

Keller, R. E. (1987). Cell rearrangement in morphogenesis. Zool. Sci. 4, 763-779.

Keller, R. E. (1991). Early embryonic development of Xenopus laevis. In Xenopus laevis: Practical Uses in Cell and Molecular Biology. Methods in Cell Biology 36, (ed. B. Kay and B. Peng), pp. 59-111. New York: Academic Press.

Keller, R. E. and Shoenwolf, G. C. (1977). An SEM study of celluar morphology, contact and arrangement, as related to gastrulation in Xenopus laevis. Wilhelm. Roux Arch. Dev. Biol. 182, 165-186.

Keller, R. E., Danilchik, M., Gimlich, R. and Shih, J. (1985a) Convergent extension by cell intercalation during gastrulation of Xenopus laevis. In Molecular Determinants of Animal Form (ed. G. M. Edelman), pp. 111-141. New York:Alan R. Liss, Inc.

Keller, R. E., Danilchik, M., Gimlich, R. and Shih, J. (1985b). The function of convergent extension during gastrulation of Xenopus laevis. $J$. Embryol. Exp. Morph. 89Supplement, 185-209.

Keller, R. E. and Hardin, J. D. (1987). Cell behavior during active cell rearrangement: evidence and speculations. J. Cell Sci. Supplement 8, 369393.

Keller, R. E. and Danilchik, M. (1988). Regional expression, pattern and timing of convergence and extension during gastrulation of Xenopus laevis. Development 103, 193-210.

Keller, R. E. and Tibbetts, P. (1989). Mediolateral cell intercalation in the dorsal axial mesoderm of Xenopuslaevis.Dev. Biol. 131, 539-549.

Keller, R. E., Cooper, M. S., Danilchik, M., Tibbetts, P. and Wilson, P. A. (1989a). Cell intercalation during notochord development in Xenopus laevis. J. Exp. Zool. 251, 134-154.

Keller, R. E., Shih, J. and Wilson, P. A. (1989b): Morphological polarity of intercalating deep mesodermal cells in the organizer of Xenopus laevis gastrulae. In Proceedings of the 47th annual meeting of the Electron Microscopy Society of America, p. 840.San Francisco Press.

Keller, R. E., Shih, J. and Wilson, P. A. (1991a). Cell motility, control and function of convergence and extension during gastrulation of Xenopus. In Gastrulation: Movements, Patterns, and Molecules. (ed. R. Keller, W. Clark and F. Griffin), pp. 101-119. New York: Plenum Press.

Keller, R., Shih, J., Wilson, P. A. and Sater, A. K. (1991b): Patterns of cell motility, cell interactions, and mechanism during convergent extension in Xenopus. In Cell-cell Interactions in Early Development. (ed. J. C. Gerhart) Society for Developmental Biology, 49th Symposium, pp. 3162.

Keller, R. E., Shih, J. and Sater, A. K. (1992a). The cellular basis of the convergence and extension of the Xenopus neural plate. Dev. Dynamics, 193, 199-217.

Keller, R. E., Shih, J., Sater, A. K. and Moreno, C. (1992b). Planar induction of convergence and extension of the neural plate by the organizer of Xenopus. Dev. Dynamics, 193, 218-234.

Keller, R., Shih, J. and Domingo, C. (1992c). The patterning and functioning of protrusive activity during convergence and extension of the Xenopus organiser. Development 1992 Supplement (in press).

Keller, R. and Jansa, S. (1992) Gastrulation in embryos of Xenopus without a blastocoel roof. Submitted.

Kimelman, D., Abraham, J., Haasparanta, T., Palisi, T. and Kirschner, M. (1988). The presence of fibroblast growth factor in the frog egg, its role as a natural mesoderm inducer. Science 242, 1053-1056.

Kintner, C. R. and Brockes, J. P. (1984). Monoclonal antibodies identify blastemal cells derived from dedifferentiating muscle in newt limb regeneration. Nature 308, 67-69.

Mangold, O. (1933). Uber die Induktionsfahigkeit der verschiedenen Bezirke der Neurula von Urodelen. Naturwissenschaften 21, 761-766.

Nakatsuji, N. (1975). Studies on the gastrulation of amphibian embryos: Cell movement during gastrulation in Xenopus laevis embryos. Wilhelm Roux Arch. Dev. Biol. 178, 1-14.

Nakatsuji, N. (1984). Cell locomotion and contact guidance in amphibian gastrulation. Am. Zool. 24, 615-627.

Nakatsuji, N. and Johnson, K. E. (1983). Conditioning of a culture substratum by the ectodermal layer promotes attachment and oriented locomotion by amphibian gastrula mesodermal cells. J. Cell Sci. 59, 4360

Nieuwkoop, P. (1969a). The formation of the mesoderm in urodelean amphibians. I. Induction by the endoderm. Wilhelm Roux Arch. EntwMech. Org. 162, 341-373.

Nieuwkoop, P. (1969b). The formation of the mesoderm in urodelean amphibians. II. the origin of the dorsoventral polarity of the mesoderm. Wilhelm Roux Arch. EntwMech. Org. 163, 298-315.

Nieuwkoop, P. D. (1973). The 'organization center' of the amphibian embryo: its origin, spatial organization, and morphogenetic action. Adv. Morph. 10, 1-39.

Schechtman, A. M. (1942). The mechanics of amphibian gastrulation. I. Gastrulation-producing interactions between various regions of an anuran egg (Hyla regilia). Univ. Calif. Publ. Zool.51, 1-39.

Schoenwolf, G. C. and Alvarez, I. C. (1989). Roles of neuroepithelial cell rearrangement and division in shaping the avian neural plate. Development 106, 427-439.

Shi, D.-L., Delarue, M., Darribère, T., Riou, J.-F. and Boucaut, J.-C. (1987). Experimental analysis of the extension of the dorsal marginal zone in Pleurodeles waltl gastrulae. Development 100, 147-161.

Shi, D.-L., Darribere, T., Johnson, K. E. and Boucaut, J.-C. (1989). Initiation of mesodermal cell migration and spreading relative to gastrulation in the urodele amphibian Pleurodeles waltl. Development 105, 351-363.

Shih, J. and Keller, R. (1992a). Cell motility driving mediolateral intercalation in explants of Xenopus. Development 116.

Shih, J. and Keller, R. (1992b) The epithelium of the dorsal marginal zone of Xenopus has organizer properties. Development $\mathbf{1 1 6}$

Slack, J. M. W., Darlington, D. G., Heath, J. K. and Godsave, S. F. (1987). Mesoderm induction in early Хenopus embryos by heparin binding growth factors. Nature 326, 197-200.

Smith, J., Yaqoob, M. and Symes, K. (1988). Purification, partial characterization and biological effects of the XTC mesoderm-inducing factor. Development 103, 591-600.

Spemann, H. (1938). Embryonic Development and Induction. New York: Yale University Press.

Spemann, H. and Mangold, H. (1924). Uber Induktion von Embryonanlagen durch Implantation artfremder Organisatoren. Arch. mikr. Anat. EntwMech. 100, 599-638.

Stewart, R. M. (1991). The active inducing center of the embryonic body axis in Xenopus. pH. D. dissertation. University of California at Berkeley.

Sudarwati, S. and Nieuwkoop, P. (1971). Mesoderm formation in the anuran Xenopus laevis. Wilhelm Roux's Arch. EntwMech. Org. 166, 189204.

Symes, K., Yaqoob, M. and Smith, J. C. (1988). Mesoderm Induction in Xenopus laevis: Responding cells must be in contact for mesoderm formation but supression of epidermal differentiation can occur in single cells. Development 104, 609-619.

Trinkaus, J. P., Trinkaus, M. and Fink, R. (1992). On the convergent cell movements of gastrulation in Fundulus.J. Exp. Zool. 261, 40-61.

Warga, R. and Kimmel, C. (1990). Cell movements during epiboly and gastrulation in zebrafish. Development 108, 569-580.

Weliky, M., Minsuk, S., Oster, G. and Keller, R. (1992). The mechanical basis of cell rearrangement. II. Models for cell behavior driving notochord morphogenesis in Xenopus laevis. Development 113, 1231.

Wilson, P. (1990). The development of axial mesoderm in Xenopus laevis. pH.D. dissertation, University of California, Berkeley.

Wilson, P. A., Oster, G. and Keller, R. (1989). Cell rearrangement and segmentation in Xenopus: direct observation of cultured explants. Development 105, 155-166.

Winklbauer, R. (1990). Mesodermal cell migration during Xenopus gastrulation. I. Interaction of mesodermal cells with fibronectin. Dev. Biol. 142, 155-168.

Winklbauer, R. and Nagel, M. (1991). Directional mesoderm cell migration in the Xenopus gastrula. Dev. Biol. 148 573-601.

Wilson, P. A. and Keller, R. E. (1991). Cell rearrangement during gastrulation of Xenopus: direct observation of cultured explants. Development 112, 289-305.

(Accepted 24 August 1992) 